\title{
Nanostructures on fused silica surfaces produced by ion beam sputtering with Al co-deposition
}

\author{
Ying Liu ${ }^{1,2}$ (D) Dietmar Hirsch ${ }^{1} \cdot$ Renate Fechner $^{1} \cdot$ Yilin Hong $^{2} \cdot$ Shaojun $\mathrm{Fu}^{2} \cdot$ Frank Frost $^{1} \cdot$ Bernd Rauschenbach $^{1}$
}

Received: 19 August 2017 / Accepted: 8 November 2017 / Published online: 29 December 2017

(c) The Author(s) 2017. This article is an open access publication

\begin{abstract}
The ion beam sputtering (IBS) of smooth mono-elemental $\mathrm{Si}$ with impurity co-deposition is extended to a pre-rippled binary compound surface of fused silica $\left(\mathrm{SiO}_{2}\right)$. The dependence of the rms roughness and the deposited amount of $\mathrm{Al}$ on the distance from the $\mathrm{Al}$ source under $\mathrm{Ar}^{+} \mathrm{IBS}$ with $\mathrm{Al}$ co-deposition was investigated on smooth $\mathrm{SiO}_{2}$, pre-rippled $\mathrm{SiO}_{2}$, and smooth Si surfaces, using atomic force microscopy and X-ray photoelectron spectroscopy. Although the amounts of $\mathrm{Al}$ deposited on these three surfaces all decreased with increasing distance from the Al target, the morphology and rms roughness of the smooth $\mathrm{Si}$ surface did not demonstrate a strong distance dependence. In contrast to smooth $\mathrm{Si}$, the rms roughness of both the smooth and pre-rippled $\mathrm{SiO}_{2}$ surfaces exhibited a similar distance evolution trend of increasing, decreasing, and final stabilization at the distance where the results were similar to those obtained without Al co-deposition. However, the pre-rippled $\mathrm{SiO}_{2}$ surfaces showed a stronger modulation of rms roughness than the smooth surfaces. At the incidence angles of $60^{\circ}$ and $70^{\circ}$, dot-decorated ripples and roof-tiles were formed on the smooth $\mathrm{SiO}_{2}$ surfaces, respectively, whereas nanostructures of closely aligned grains and blazed facets were generated on the pre-rippled $\mathrm{SiO}_{2}$, respectively. The combination of impurity co-deposition with pre-rippled surfaces was found to facilitate the formation of novel types of nanostructures and morphological growth. The initial ripples act as a template to guide the preferential deposition of $\mathrm{Al}$ on the tops of the ripples or the ripple sides facing the $\mathrm{Al}$ wedge, but not in the valleys between the ripples, leading to $2 \mathrm{D}$ grains and quasiblazed grating, which offer significant promise in optical applications. The rms roughness enhancement is attributed not to $\mathrm{AlSi}$, but to $\mathrm{AlO}_{\mathrm{x}} \mathrm{F}_{\mathrm{y}}$ compounds originating mainly from the $\mathrm{Al}$ source.
\end{abstract}

\section{Introduction}

Low-energy ion beam sputtering (IBS) is a powerful bottom-up technology for generating diverse self-organized nanostructures, such as ripples and dots on different materials including amorphous $\mathrm{SiO}_{2}[1-7]$, single crystalline $\mathrm{Si}$ [8-12], Ge [10,13] and $\mathrm{Ag}$ [14], as well as compound semiconductors GaSb [15] and InP [16]; the IBS technology offers the potential to achieve high throughput and fabrication of large areas [10,17-19]. Ion beam parameters

Ying Liu

liuychch@ustc.edu.cn

Frank Frost

frank.frost@iom-leipzig.de

1 Leibniz-Institut für Oberflächenmodifizierung e.V., Permoserstraße 15, 04318 Leipzig, Germany

2 National Synchrotron Radiation Laboratory, University of Science and Technology of China, Hezuohua South Road 42, Hefei 230029, People's Republic of China (species, incidence angle, energy, flux, etc) and substrate parameters (material, temperature, initial surface topography, etc) interact to generate the features of such nanopatterns. Recently, numerous experiments on sputtering with simultaneous co-deposition [20-39] and theoretical studies [40-47] on simultaneous metal co-deposition during IBS or surfactant sputtering [32-38, 46, 47] have been performed to elucidate the formation mechanism of self-organized nanostructures and to generate various nanopatterns. In principle, the simultaneous use of metal atoms modulates the sputtering yield of the substrate during IBS, which results in diverse physical and chemical phenomena (e.g., island formation or phase separation). Silicide induced by metal co-deposition has been generally considered to contribute significantly to the formation of Si nanostructures during Si erosion at normal or near normal incidences to the ion beam.

To date, extensive research has been conducted on the ion erosion of smooth Si surfaces under simultaneous codeposition of metals at normal or near normal incidences. However, very few co-deposition studies have been reported 
on either compound materials or pre-patterned substrates. Only one work investigates $\mathrm{Al}$ co-deposition on $\mathrm{SiO}_{2}$ films that were thermally grown on $\mathrm{Si}$ [30], and this work did not focus on patterning, showing only the development of an $\mathrm{Al}$ thickness gradient on the $\mathrm{SiO}_{2}$.

In fact, nanostructures on compound surfaces are considered especially promising for a wide range of applications. For example, nanopatterned $\mathrm{SiO}_{2}$ [48-51] may offer superior performance as an anti-reflective surface in the deep ultraviolet spectral range for applications in lasers, solar cells, etc, and as quantum nanostructures on III-V semiconductor surfaces [52-54] in optoelectronics and quantum optics. Moreover, according to available experimental and simulation data, pre-patterned surfaces have shown great potential for generating novel or highly ordered patterns, or even gratings [55-58]. In addition, IBS may prove to be a fast and cost-effective nanofabrication tool for large area nanostructures with critical dimensions or wavelengths in the vicinity of $100 \mathrm{~nm}$. Therefore, in this study, the IBS of a compound with metal co-deposition-specifically, of fused silica with Al co-deposition-will be investigated. To understand the formation and evolution mechanisms of such nanostructures, several comparisons will be performed between smooth and pre-rippled fused silica, smooth fused silica, and $\mathrm{Si}$.

Fused silica is a typical and widely available compound of Si that contains only silicon and oxygen, and this compound is an important material for technical applications in many fields. Previous work on the ion erosion of $\mathrm{SiO}_{2}$ revealed that pattern formation without co-deposition is enhanced when the erosion is implemented on pre-patterned surfaces rather than smooth surfaces [6]. Therefore, Al co-deposition on fused silica may further accelerate the morphology evolution and generate novel nanostructures.

Aluminum was selected as the co-deposition material for this study for the following reasons. First, the aspect ratio of fused silica can be enhanced by leveraging the difference in the sputter yields of fused silica and $\mathrm{Al}_{2} \mathrm{O}_{3}$ [7]. Second, to date, no work has been reported on the ion erosion of $\mathrm{Si}$ with $\mathrm{Al}$ co-deposition. Third, $\mathrm{Al}$ is often present in ion beam etching machines, and $\mathrm{Al}$ contaminations may affect the surface topography of fused silica in the ion beam etching or machining of this material. This last consideration is particularly relevant to applications in which the microroughness of ion beam-processed optical elements is a crucial parameter.

Therefore, in this study, a setup similar to that of Hofsäss et al. [32] was used to achieve IBS of fused silica with Al co-deposition. The $\mathrm{Al}$ concentration changed with the distance from an $\mathrm{Al}$ wedge to the samples. The formation of Al-fused silica nanostructures was analyzed and compared to analogous results for pure $\mathrm{Si}$ substrates using atomic force microscopy (AFM) and X-ray photoelectron spectroscopy (XPS). Section 2 introduces the experimental setup. Section 3 presents and discusses the morphologies achieved by sputtering with $\mathrm{Al}$ co-deposition and the relationship between the morphologies and the amount of $\mathrm{Al}$ deposited. The final section presents the study's conclusions.

\section{Experimental methods}

The initial root mean square (rms) roughnesses of the fused silica (hereinafter denoted as $\mathrm{SiO}_{2}$ ) and $\mathrm{Si}$ wafers were approximately 0.4 and $0.15 \mathrm{~nm}$, respectively. All samples were cut to a typical size of $30 \mathrm{~mm}$ (in the $x$ direction) $\times 15 \mathrm{~mm}$ (in the $z$ direction), as shown in Fig. 1. Ion bombardment experiments were performed using a system constructed by some of the authors for the purpose of these experiments [10]. The diameter of the Kaufman-type broad beam ion source was approximately $180 \mathrm{~mm}$. The IBS was performed with a $400 \mathrm{eV}$ Ar ion beam with a beam current of $70 \mathrm{~mA}$ for a duration of $20 \mathrm{~min}$, corresponding to a fluence of $1.1 \times 10^{18}$ ions $/ \mathrm{cm}^{2}$ in the plane perpendicular to the ion beam. Metal co-deposition was achieved with an $\mathrm{Al}$ target, positioned adjacent to the $\mathrm{SiO}_{2}$ or $\mathrm{Si}$ samples, as shown in Fig. 1. The target's specifications identified the composition as $98.7 \% \mathrm{Al}, 0.29 \% \mathrm{Si}, 0.27 \% \mathrm{Mg}, 0.52 \% \mathrm{~F}$, and $0.06 \% \mathrm{Fe}$. The target was an $\mathrm{Al}$ wedge with an apex angle of $20^{\circ}$, so that the angle of the surface between a sample and the wedge was fixed to $110^{\circ}$. During sputtering, both the samples and the wedge were exposed to the ion beam. A fraction of $\mathrm{Al}$ atoms that sputtered off the wedge was directly deposited onto the sample surface, which could affect the final morphology of the sample surface, and even generate self-organized patterns. The incidence angles of the ion beam upon the sample and the $\mathrm{Al}$ wedge, denoted as $\theta_{\mathrm{s}}$ and $\theta_{\mathrm{t}}$, respectively, were defined as the angles between each surface normal and the ion beam, as shown in Fig. 1. The

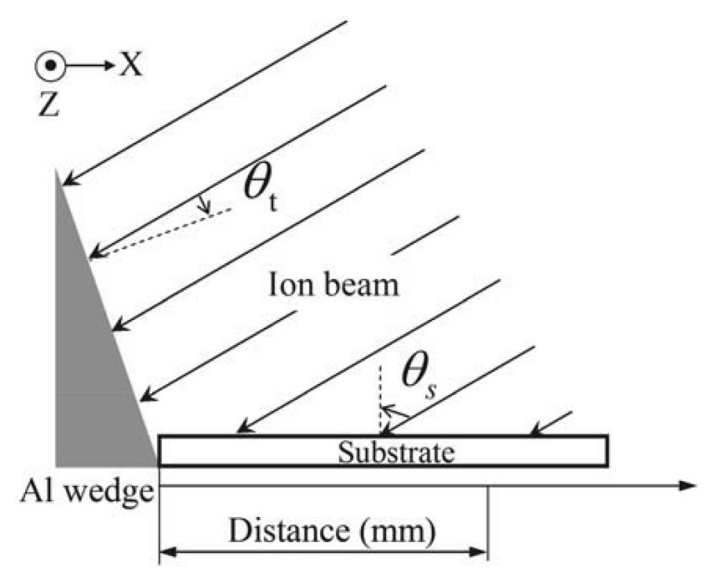

Fig. 1 Schematic diagram of the experimental setup for IBS with Al co-deposition 
incidence angles discussed hereinafter refer to those between the ion beam and the normal of the samples, $\theta_{\mathrm{s}}$.

The surface morphologies of the sputtered $\mathrm{SiO}_{2}$ and $\mathrm{Si}$ samples were characterized by an AFM working in tapping mode within an area of $2 \times 2 \mu \mathrm{m}^{2}$ and with a resolution of $1024 \times 1024$ pixels. The AFM data were analyzed with SPIPTM software [59]. Consequently, XPS analysis of the samples was performed to determine the concentration of deposited materials as a function of the distance to the Al target. XPS measurements were performed using monochromatic $\mathrm{Al} \mathrm{K} \alpha$ radiation and a concentric hemispherical analyzer (CHA). The collected spectra were analyzed with Unifit 2015 software [60], and concentration calculations were performed using the Unifit software in conjunction with theoretical photoionization cross-sections, calculated electron mean-free paths, and experimentally determined instrument transmission functions.

\section{Results and discussion}

Section 3.1provides a general overview of the evolving $\mathrm{SiO}_{2}$ surface pattern depending on the ion incidence angle. In Sects. 3.2 and 3.3, the variations of the $\mathrm{SiO}_{2}$ surface topography associated with two selected ion incidence angles are discussed in more detail. In particular, the topography's dependence on the distance from the $\mathrm{Al}$ wedge (i.e., the $\mathrm{Al}$ concentration) is discussed. In addition, the similarities and differences between the ripple development on smooth and pre-patterned surfaces are shown. Section 3.4 compares the surface evolution of the $\mathrm{SiO}_{2}$ with that of the $\mathrm{Si}$ with simultaneous Al co-deposition. Section 3.5 presents the XPS analysis of the ion sputtered surface with simultaneous $\mathrm{Al}$ co-deposition. Finally, Sect. 3.6 discusses the formation mechanism of the surface patterns.

\subsection{Incidence angle dependence of smooth $\mathrm{SiO}_{2}$ morphology treated by IBS with AI co-deposition}

Figure 2 shows the incidence angle dependence of the morphology evolution of a $\mathrm{SiO}_{2}$ wafer under IBS and $\mathrm{Al}$ codeposition. The AFM images were taken at a position $2 \mathrm{~mm}$ from the $\mathrm{Al}$ target edge. In addition, to provide a clear picture of each irradiation condition, the sputtering geometry at each incidence angle is shown in Fig. $2\left(b^{\prime}-f^{\prime}\right)$, respectively. In principle, a given location on the $\mathrm{SiO}_{2}$ wafer in front of the $\mathrm{Al}$ target received $400-\mathrm{eV} \mathrm{Ar}$ ions, sputtered $\mathrm{Al}$ atoms, and Ar particles backscattered from the $\mathrm{Al}$ target. The effect of the backscattered Ar particles upon $\mathrm{SiO}_{2}$ surfaces is insignificant, and therefore, the effect is omitted in the discussion.

Figure $3 \mathrm{a}$ and $\mathrm{b}$ show the incidence angle dependence on rms roughness and on the power spectral density (PSD) evolution, respectively, of the surface under IBS with Al codeposition. At low incidence angles $\left(\theta_{\mathrm{s}}<40^{\circ}\right)$, the surfaces remained smooth with a roughness of approximately $0.4 \mathrm{~nm}$. When self-organized nanostructures were generated at larger incidence angles of $60^{\circ}$ and $70^{\circ}$, the rms roughness of these surfaces increased. The PSDs of ion incidence angles less than $40^{\circ}$ were similar to each other but different from those of incidence angles of $60^{\circ}$ and $70^{\circ}$. The incidence angle dependence of $\mathrm{rms}$ roughness of $\mathrm{SiO}_{2}$ with $\mathrm{Al}$ co-deposition was very similar to those previously reported for $\mathrm{SiO}_{2}$ [5], $\mathrm{Si}$ [22], and Ge [13] without metal co-deposition.

Most of the recent investigations of sputtering with metal co-deposition have been conducted on $\mathrm{Si}$ surfaces at normal incidences to the ion beam. For Si surfaces, dot patterns have been generated at or near normal incidences with concurrent metal deposition. However, in our study, no pattern was generated on $\mathrm{SiO}_{2}$ at the incidence angle of $\theta_{\mathrm{s}}<40^{\circ}$ even with $\mathrm{Al}$ co-deposition. This indicated a remarkable pattern formation difference between $\mathrm{Si}$ and $\mathrm{SiO}_{2}$, which may be due to different chemical products and their effects upon the pattern formation and growth.

The following subsection details the investigations into sputtering at the incidence angles $\theta_{\mathrm{s}}$ of $60^{\circ}$ and $70^{\circ}$, which correspond to incidence angles $\theta_{\mathrm{t}}$ of $10^{\circ}$ and $0^{\circ}$, respectively, between the ion beam and the normal of the sputtered surface of the Al wedge.

\subsection{Distance dependence of smooth $\mathrm{SiO}_{2}$ morphology treated by oblique IBS with AI co-deposition}

Typical AFM images of the surface morphologies of smooth $\mathrm{SiO}_{2}$ at distances between $2 \mathrm{~mm}$ and more than $20 \mathrm{~mm}$ from the $\mathrm{Al}$ wedge are shown for incidence angles of $60^{\circ}$ (Fig. 4) and $70^{\circ}$ (Fig. 5). To provide further insight into the effect of Al co-deposition, the rms roughnesses and XPS analyses of the samples are shown in Fig. 6. The rms roughnesses in Fig. 6a were calculated from the AFM data in Figs. 4 and 5.

\subsubsection{Differences between incidence angles of $60^{\circ}$ and $70^{\circ}$}

Different nanostructures were formed at each incidence angle. As shown in Fig. 4, ripples decorated with dots were generated on the surface at $60^{\circ}$, which was very similar to a previously reported $\mathrm{Si}$ surface nanopatterned during an oblique $40 \mathrm{keV} \mathrm{Ar}{ }^{+}$erosion with $\mathrm{Fe}$ co-deposition at the same incidence angle [28]. In contrast, at $70^{\circ}$, roof-tiles developed on the surface along the direction of the wave vector of an ion-induced ripple (Fig. 5). These results demonstrate that the incidence angle of the ion beam is a very important parameter relevant to generating different nanostructures. 

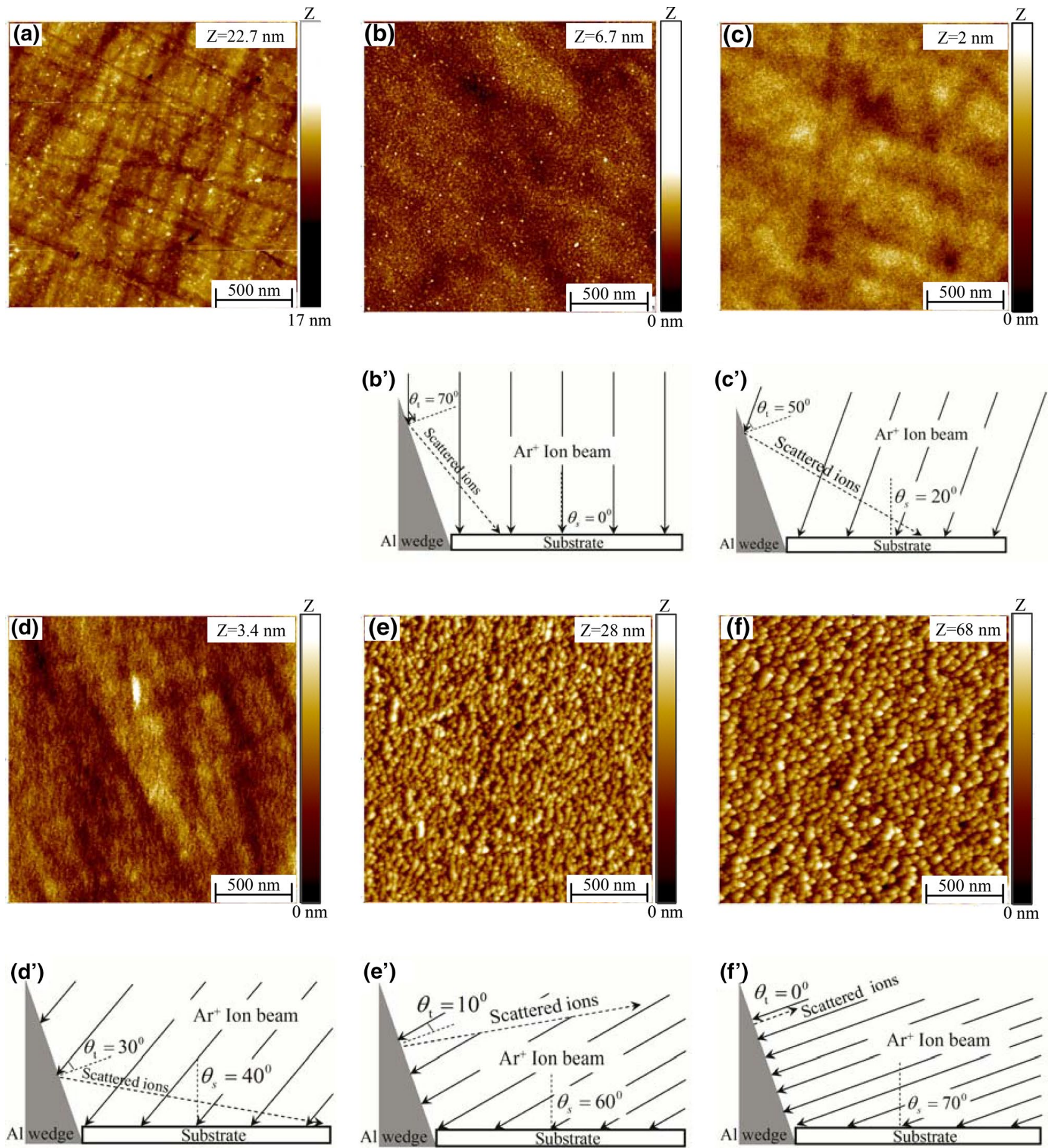

(e')

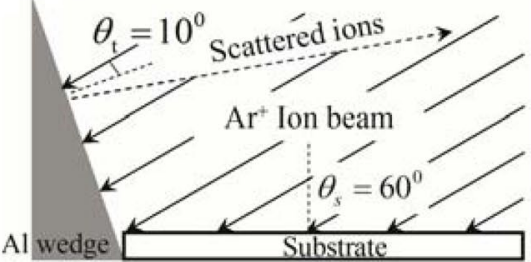

(f')

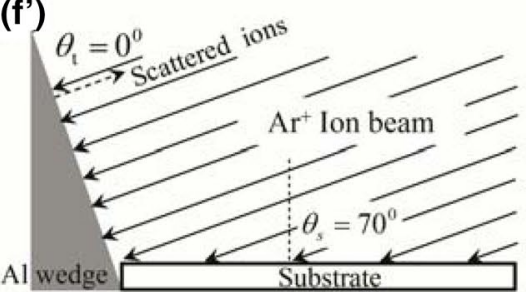

Fig. 2 AFM images $\left(2 \times 2 \mu \mathrm{m}^{2}\right)$ of $\mathrm{SiO}_{2}$ surfaces sputtered at a distance of $2 \mathrm{~mm}$ from the $\mathrm{Al}$ wedge edge as a function of incidence angle. a Initial substrate, $\mathbf{b} 0^{\circ}, \mathbf{c} 20^{\circ}, \mathbf{d ~} 40^{\circ}, \mathbf{e ~} 60^{\circ}$, and $\mathbf{f} 70^{\circ}$. $\mathbf{b}^{\prime}-\mathbf{f}^{\prime}$ Show the sputtering geometry of each incidence angle with Al co-deposition

The results for the incidence angle of $70^{\circ}$ showed sharper morphological and rms roughness transitions than those at $60^{\circ}$. As shown in Fig. 6a, the distances corresponding to the rms roughness maxima at $60^{\circ}$ and $70^{\circ}$ were 12 and $6 \mathrm{~mm}$, respectively. In addition, the rms roughnesses of the samples stabilized at the distances of 20 and $11 \mathrm{~mm}$, respectively; at these positions, the samples would be sufficiently distant from the $\mathrm{Al}$ wedge that co-deposition would not occur. The distances corresponding to both the roughness maxima and stabilization at $70^{\circ}$ were clearly less than those at $60^{\circ}$. These differences in the morphological and rms roughness evolutions induced by incidence angles of $60^{\circ}$ and $70^{\circ}$ indicated 

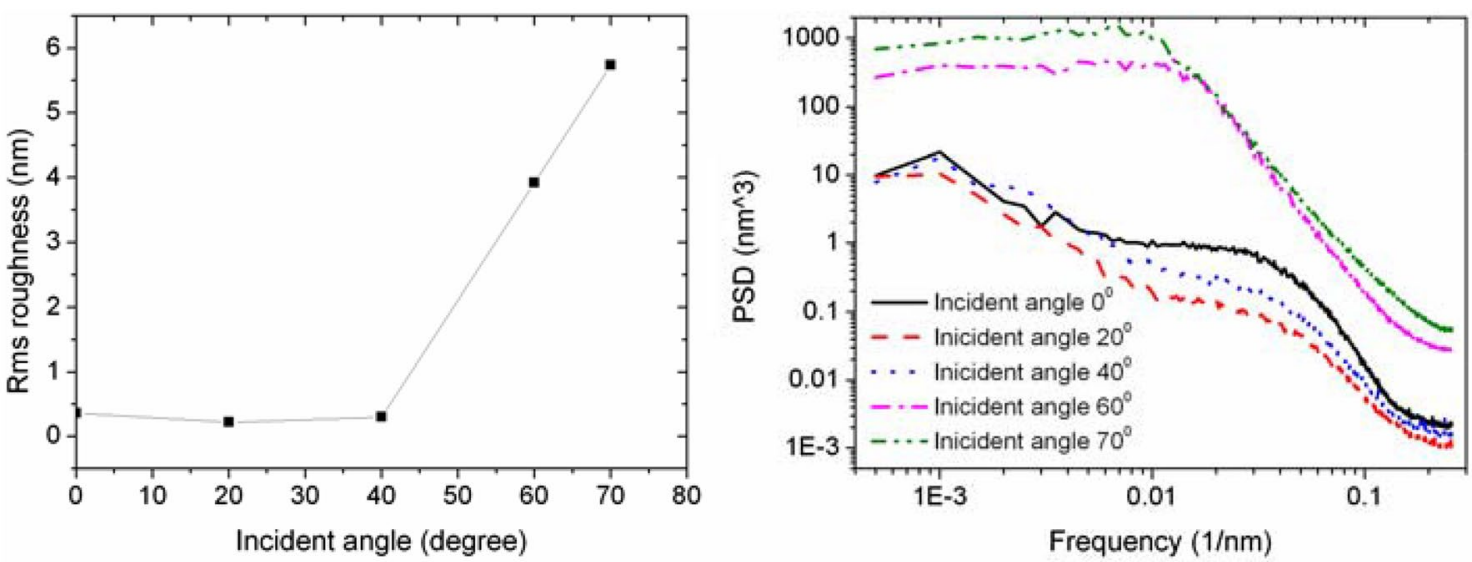

Fig. 3 a Rms roughness as a function of incidence angle $\theta s$ at a distance of $2 \mathrm{~mm}$ from the Al wedge's edge. b PSD curves for different incidence angles at a distance of $2 \mathrm{~mm}$ from the $\mathrm{Al}$ wedge's edge

a difference in the deposition-sputtering ratios of $\mathrm{Al}$ and $\mathrm{Ar}$ flux $\Phi_{\mathrm{Al}} / \Phi_{\mathrm{Ar}}$ at each incidence angle, with a larger $\Phi_{\mathrm{Al}} / \Phi_{\mathrm{Ar}}$ ratio resulting in a faster pattern evolution. Hence, the $\Phi_{\mathrm{Al}} / \Phi_{\mathrm{Ar}}$ at $70^{\circ}$ was considered to be larger than that at $60^{\circ}$.

Most works on IBS with metal co-deposition have been conducted under normal incidences of the ion beam. The two most relevant reports on the IBS of Si with metal codeposition at oblique angles have been published by (A) Redondo-Cubero et al. [28] and (B) Moon et al. [31]. In these papers, IBS was conducted at an incidence angle of $60^{\circ}$ with $\mathrm{Fe}$ co-deposition (silicide-forming metal) and at $75^{\circ}$ with Au co-deposition (non-silicide forming metal), respectively. Compared to the results reported by RedondoCubero et al. [28], our investigation demonstrated a similar ripple decorated with dots on the smooth $\mathrm{SiO}_{2}$ at the incidence angle of $60^{\circ}$. However, we did not observe a morphological transition similar to that observed by Moon et al.

\subsubsection{Similarity of rms roughness dependence on distance for both incidence angles}

In both cases, with increasing distance, the rms roughness of the morphologies increased, then decreased, and finally stabilized at the level of roughness obtained without $\mathrm{Al}$ codeposition (shown by the dashed and dotted lines in Fig. 6a). However, with increasing distance to the $\mathrm{Al}$ target, the content of the $\mathrm{Al}$ co-deposition on the surface reduced only monotonously, whereas that of Si increased (Fig. 6b, c). A similar dependence of rms roughness upon the co-deposited metal content has also been observed in investigations of IBS Si patterning with Fe co-deposition [25]. The evolution of rms roughness can be divided into three regions as described in the following.

In Region I, the rms roughness increased with decreasing $\mathrm{Al}$ content. In other words, the rms roughness decreased with increasing $\mathrm{Al}$ content, which can clearly be attributed to the deposition of the Al film. Therefore, the main patterning mechanism in this region is controlled by the deposition. Such a smoothing effect due to increasing impurity content has also been reported in the IBS of Si with concurrent Au [32] and $\mathrm{Fe}[25,29]$ depositions.

In Region II, the rms roughness increased with increasing $\mathrm{Al}$ content. The $\mathrm{Al}$ deposition's enhancement of the rms roughness is pronounced in this region; this effect can be attributed to the coupled effects of the ion beam sputtering and the simultaneous directional deposition with a particular sputtering and co-deposition geometry.

In Region III, with increasing distance from the $\mathrm{Al}$ wedge, the co-deposition of $\mathrm{Al}$ upon the samples became almost zero, and the rms roughness decreased to the value obtained without $\mathrm{Al}$ co-deposition. In this region, physical sputtering based on a Bradley-Harper (BH) [61] model dominated the pattern generation.

\subsection{Distance dependence of pre-rippled $\mathrm{SiO}_{2}$ morphology treated by oblique IBS with AI co-deposition}

We used pre-rippled samples to investigate the effects of the initial surface topography or roughness on the topography evolution with simultaneous $\mathrm{Al}$ co-deposition. The prepatterned ripples were prepared by sputtering for $120 \mathrm{~min}$ with $1200 \mathrm{eV} \mathrm{Kr}$ ions at an incidence angle of $53^{\circ}$ and a total fluence of $1.26 \times 10^{19} \mathrm{ions} / \mathrm{cm}^{2}$.

The evolved surface morphologies are shown in Figs. 7 and 8 for ion incidence angles of $60^{\circ}$ and $70^{\circ}$, respectively. Figures $7 \mathrm{f}$ and $8 \mathrm{f}$ present the pre-patterned surface, both with similar ripple wavelengths (approximately $110 \mathrm{~nm}$ ) and roughness values (approximately $6.7 \mathrm{~nm}$ ). For an incidence angle of $60^{\circ}$, the ion beam direction was parallel to 

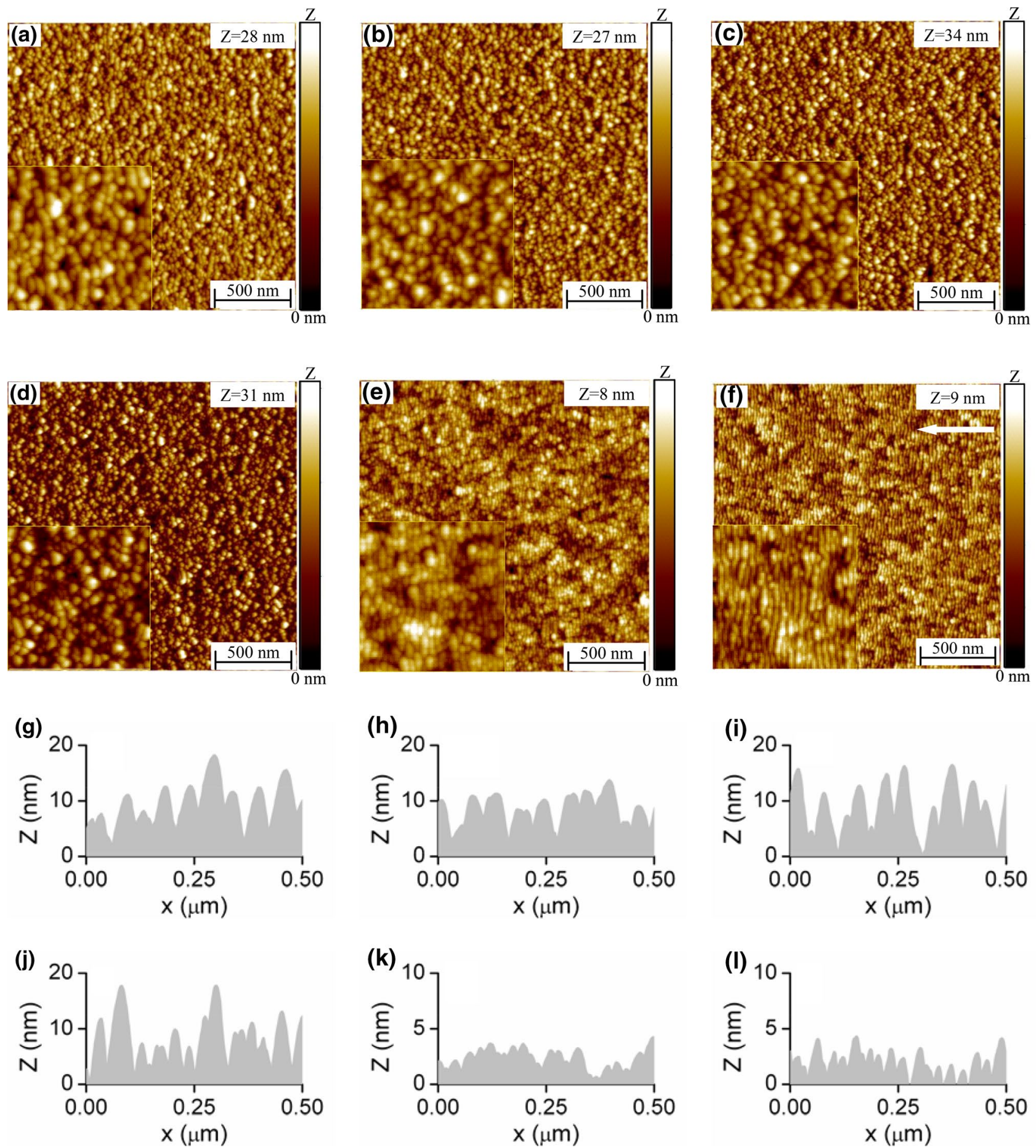

Fig. 4 Typical AFM images of smooth $\mathrm{SiO}_{2}$ samples after sputtering with $\mathrm{Al}$ co-deposition at an incidence angle of $60^{\circ}$ at distances from the $\mathrm{Al}$ target of a $2 \mathrm{~mm}, \mathbf{b} 6 \mathrm{~mm}, \mathbf{c} 10 \mathrm{~mm}$, d $12 \mathrm{~mm}$, e $30 \mathrm{~mm}$, and f without $\mathrm{Al}$ co-deposition. All images were obtained with the ion

the initial ripple pattern (i.e., perpendicular to the vector of the pre-ripple), whereas at $70^{\circ}$ the ion beam direction was perpendicular to the initial ripple pattern (i.e., parallel to the vector of the pre-ripple). The rest of this subsection beam direction, which is indicated by a white arrow in $\mathbf{f}$. The area shown by each image is $2 \times 2 \mu \mathrm{m}^{2}$, and the magnified insets show areas of $0.5 \times 0.5 \mu \mathrm{m}^{2}$. $\mathbf{g}-\mathbf{l}$ Height profiles along lines parallel to the ion beam directions in $\mathbf{a}-\mathbf{f}$, respectively

compares the results of pre-rippled substrates with those of smooth substrates. 

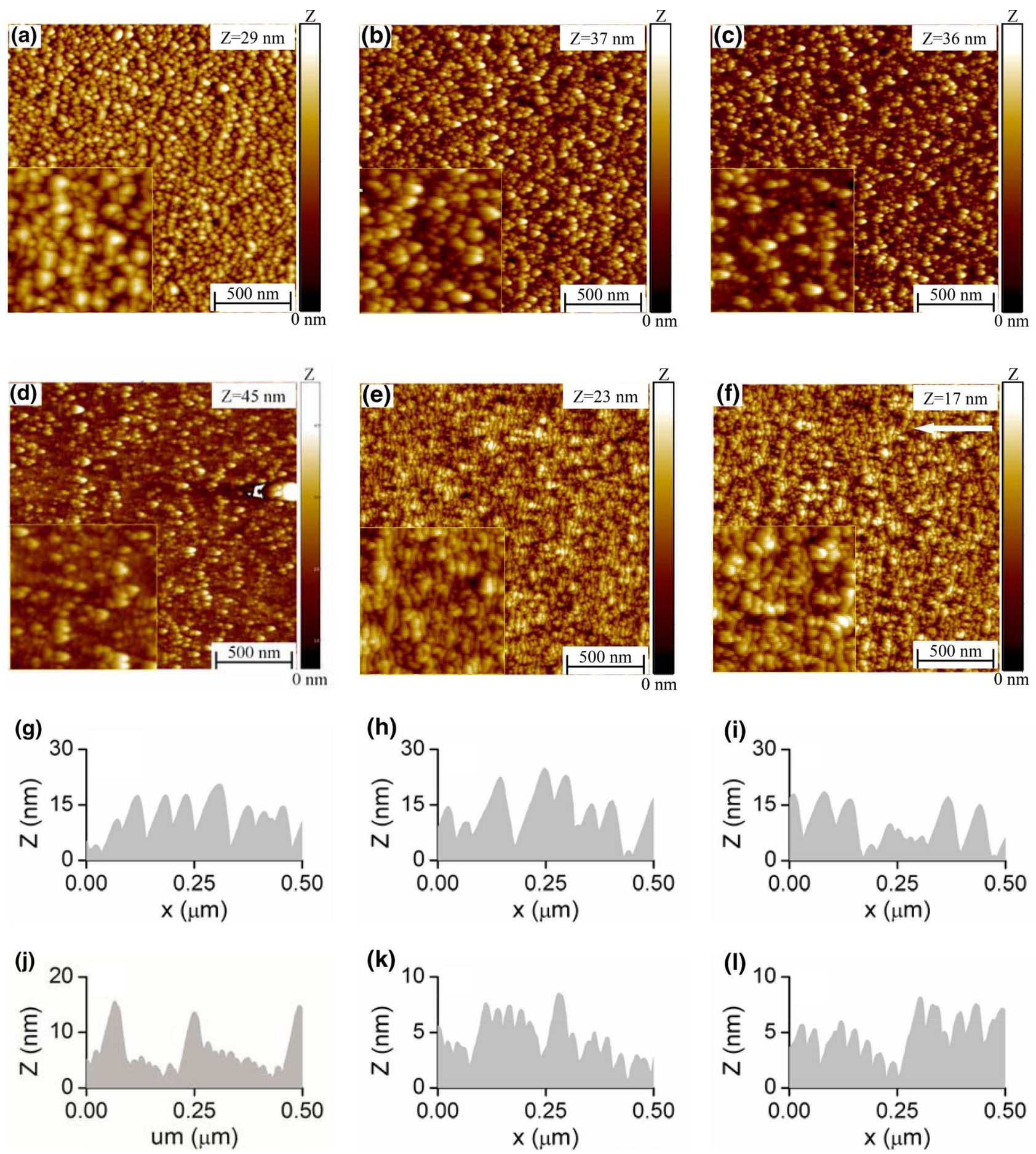

Fig. 5 Typical AFM images of smooth $\mathrm{SiO}_{2}$ samples after sputtering with $\mathrm{Al}$ co-deposition at an incidence angle of $70^{\circ}$ at distances from the Al target of: a $2 \mathrm{~mm}$, b $6 \mathrm{~mm}$, c $7 \mathrm{~mm}, \mathbf{d} 8 \mathrm{~mm}$, e $20 \mathrm{~mm}$, and f without $\mathrm{Al}$ co-deposition. All images were obtained with the same ion beam direction, which is indicated by a white arrow in $\mathbf{f}$. The area shown by each image is $2 \times 2 \mu \mathrm{m}^{2}$, and the magnified insets show areas of $0.5 \times 0.5 \mu \mathrm{m}^{2}$. g-l Height profiles along lines parallel to the ion beam directions in $\mathbf{a}-\mathbf{f}$, respectively 
(a)
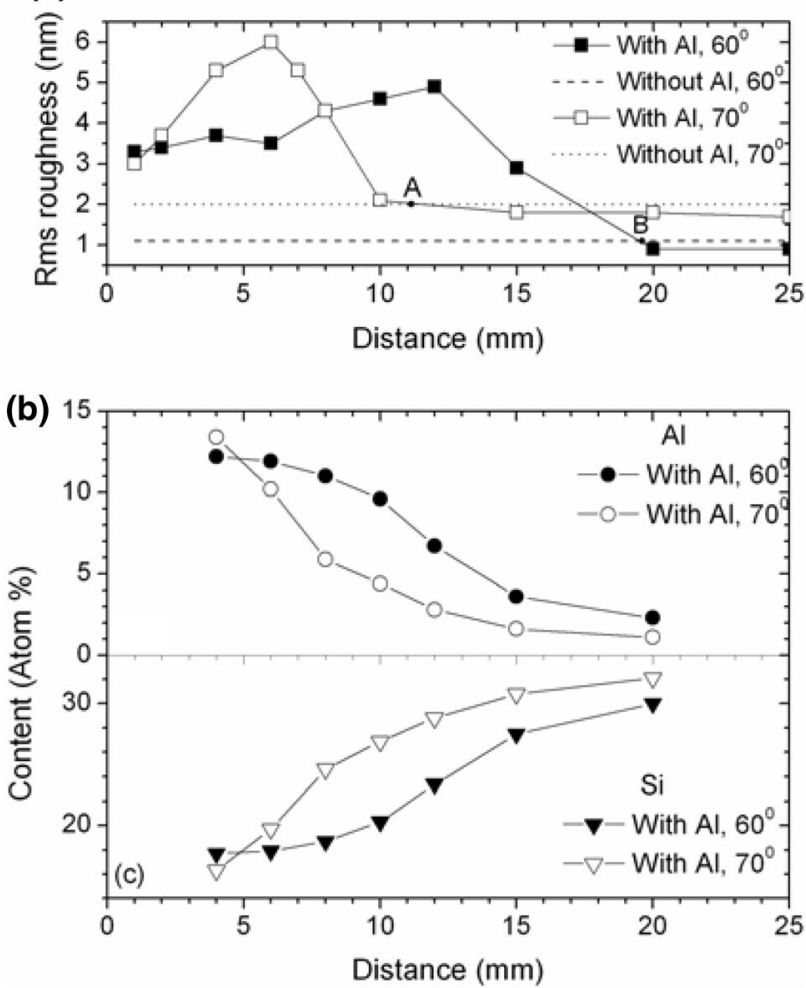

Fig. 6 Comparison of distance dependence of a rms roughness and contents of b $\mathrm{Al}$ and $\mathbf{c} \mathrm{Si}$ for smooth $\mathrm{SiO}_{2}$ substrates at incidence angles of $60^{\circ}$ and $70^{\circ}$. The horizontal dashed and dotted lines in a correspond to the roughness of the sputtered substrates without $\mathrm{Al}$ co-deposition at incidence angles of $60^{\circ}$ and $70^{\circ}$, respectively. Points $\mathrm{A}$ and $\mathrm{B}$ in $\mathbf{a}$ indicate the positions at which the effect of Al deposition on morphology can be considered negligible

\subsubsection{Comparison of morphological pattern types of pre-rippled and smooth $\mathrm{SiO}_{2}$ surfaces}

Different morphological pattern types were present on the pre-rippled $\mathrm{SiO}_{2}$ at each incidence angle. At an incidence angle of $60^{\circ}$, the initial ripple pattern was not clearly recognizable at short distances from the $\mathrm{Al}$ wedge (Fig. 7a, b), and the surface morphology was dominated by a grain- or cauliflower-like structure. Figure 7e shows a two-dimensional (2D) ripple pattern after sputtering at $60^{\circ}$ without $\mathrm{Al}$ co-deposition; one ripple in Fig. 7e with a larger wavelength of approximately $100 \mathrm{~nm}$ originated from the initial pre-rippled surface, whereas the other new ripple with a smaller wavelength of approximately $20 \mathrm{~nm}$ and a ripple vector perpendicular to that of the first ripple vector was generated because the IBS direction was perpendicular to the vector of the initial pre-ripple. The 2D-ripple shows the ripple superimposition induced by the sequential IBS of the $\mathrm{SiO}_{2}$ surfaces. The final grain- or cauliflower-like structure arises from the comprehensive effect of both the IBS and the concurrent $\mathrm{Al}$ co-deposition guided by the rippled surfaces.
At an incidence angle of $70^{\circ}$, faceted structures appeared on the pre-rippled $\mathrm{SiO}_{2}$ surfaces, as shown in Fig. 8a, b. With the increasing amount of $\mathrm{Al}$ deposition, the edge of the blazed profile becomes increasingly smooth. A quasi-blazed grating, i.e., a blazed pattern with a little rough edge can be achieved with this sputtering and co-deposition geometry.

In summary, after IBS with Al co-deposition on prepatterned $\mathrm{SiO}_{2}$, novel pattern types of grains and blazed profiles are generated at incidence angles of $60^{\circ}$ and $70^{\circ}$, respectively. Such pattern types are different from the ripples decorated with dots and the roof-tile nanostructures that developed on the initial smooth $\mathrm{SiO}_{2}$, as shown in Figs. 4 and 5.

When the incidence angle was $70^{\circ}$, the separate roof-tiles on the smooth $\mathrm{SiO}_{2}$ became continuous blazed profiles on the pre-rippled $\mathrm{SiO}_{2}$. According to one sputtering investigation of $\mathrm{Si}$ with $\mathrm{Fe}$ co-deposition [12] and a simulation of surfactant sputtering [34], with pre-rippled $\mathrm{SiO}_{2}, \mathrm{Al}$ is preferentially deposited on the tops of the ripples or on the ripple sides facing the $\mathrm{Al}$ wedge, but not in the valleys between the ripples. The initial ripples act as a template that guides a directional $\mathrm{Al}$ co-deposition, resulting in the alignment and connection of deposited Al.

From a practical perspective, both the $\mathrm{SiO}_{2}$ grains and blazed profiles with the critical dimension of approximately $100 \mathrm{~nm}$ may be very attractive as potential optical devices, such as UV subwavelength optical elements or diffraction gratings with periods down to $100 \mathrm{~nm}$.

\subsubsection{Comparison of rms roughnesses of pre-rippled and smooth $\mathrm{SiO}_{2}$ surfaces}

On the one hand, some similarities can be found between the roughnesses of pre-rippled and smooth $\mathrm{SiO}_{2}$ surfaces. For example, as shown in Fig. 9, the rms roughness of rippled $\mathrm{SiO}_{2}$ evolves through increasing, decreasing, and stabilizing phases, similar to the evolution of the smooth $\mathrm{SiO}_{2}$ samples as shown in Fig. 6. Moreover, the rms roughnesses of both the smooth and pre-rippled $\mathrm{SiO}_{2}$ surfaces stabilized at a sufficiently long distance, approaching the rms roughness obtained without $\mathrm{Al}$ co-deposition.

On the other hand, differences also appeared in the rms roughness evolutions of the pre-rippled and smooth $\mathrm{SiO}_{2}$ surfaces. For rms roughness growth, at incidence angles of $60^{\circ}$ and $70^{\circ}$, the enhancement of morphological roughness from smooth to pre-rippled surfaces was pronounced, which indicates the stronger ability of a pre-rippled substrate to roughen a surface. Moreover, the maximal rms roughness of the pre-rippled $\mathrm{SiO}_{2}$ was larger than that of the smooth $\mathrm{SiO}_{2}$. In addition, the distance range corresponding to the maximal rms roughness of the pre-rippled $\mathrm{SiO}_{2}$ was slightly larger than that of the smooth $\mathrm{SiO}_{2}$. These effects can be attributed to the preferential deposition of $\mathrm{Al}$ on the tops of 

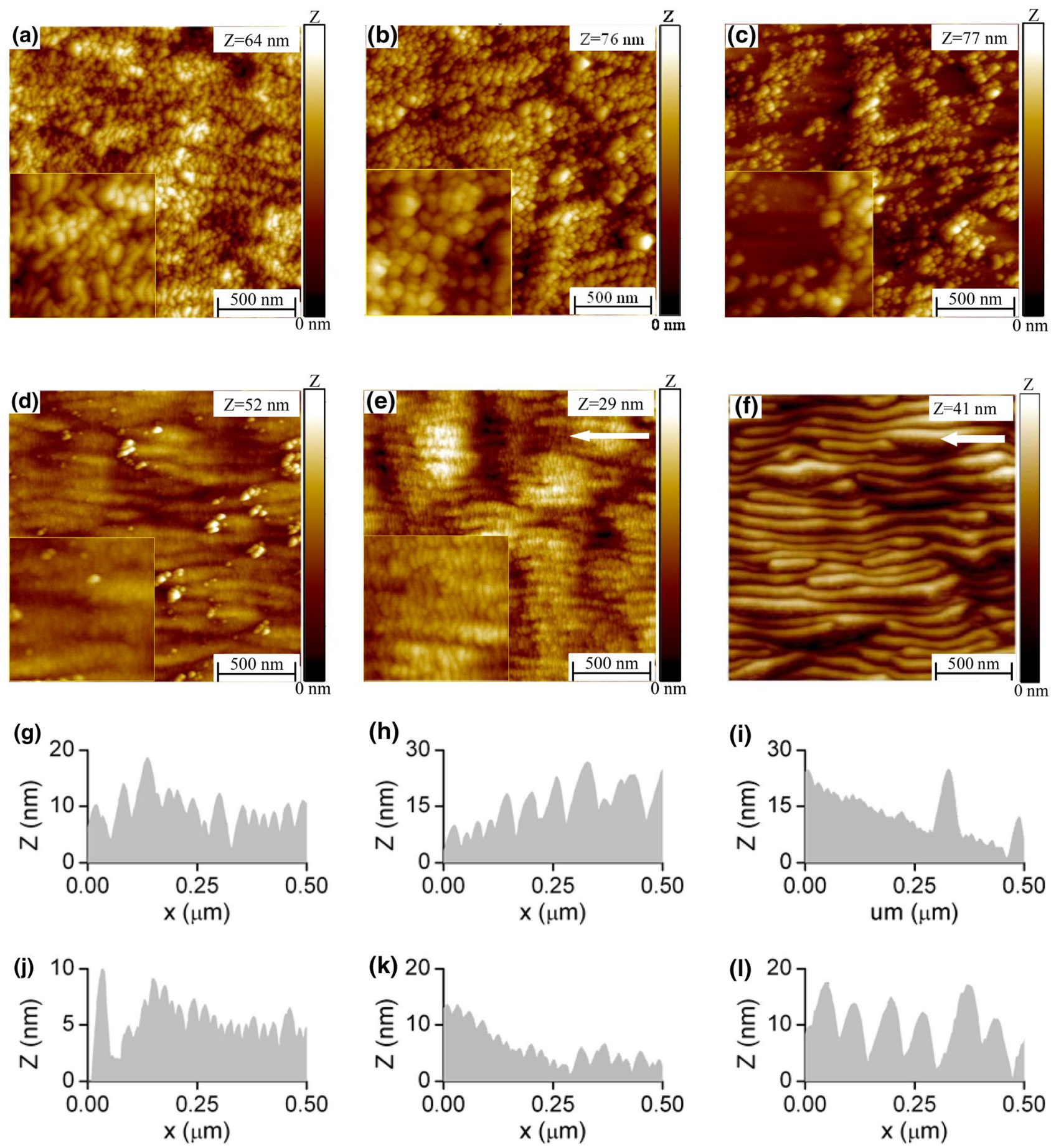

Fig. 7 Typical AFM images of pre-rippled $\mathrm{SiO}_{2}$ sample after sputtering with $\mathrm{Al}$ co-deposition at an incidence angle of $60^{\circ}$ at distances from the Al target of: a $2 \mathrm{~mm}, \mathbf{b} 8 \mathrm{~mm}$, c $15 \mathrm{~mm}$, d $25 \mathrm{~mm}$, e without $\mathrm{Al}$ co deposition, and $\mathbf{f}$ initial rippled substrate. The ion beam direction indicated by the white arrow in $\mathbf{e}$ is the same for the AFM

the ripples or the ripple sides facing the $\mathrm{Al}$ wedge, but not in the valleys between the ripples following facts, as reported in the sputtering investigation of $\mathrm{Si}$ with $\mathrm{Fe}$ co-deposition [12] and the simulation of surfactant sputtering [34]. images in $\mathbf{a}-\mathbf{e}$, and the ion beam direction of the AFM image in $7 \mathbf{f}$ is also indicated with a white arrow. The area shown by each image is $2 \times 2 \mu \mathrm{m}^{2}$, and the magnified insets show areas of $0.5 \times 0.5 \mu \mathrm{m}^{2} . \mathbf{g}-\mathbf{l}$ Height profiles along lines parallel to the ion beam direction in $\mathbf{a}-\mathbf{f}$, respectively

In summary, from the comparison of the morphologies and rms roughnesses of the pre-rippled and smooth $\mathrm{SiO}_{2}$ surfaces, the initial rippled $\mathrm{SiO}_{2}$ morphology clearly affected the nanostructure formation and fostered the 

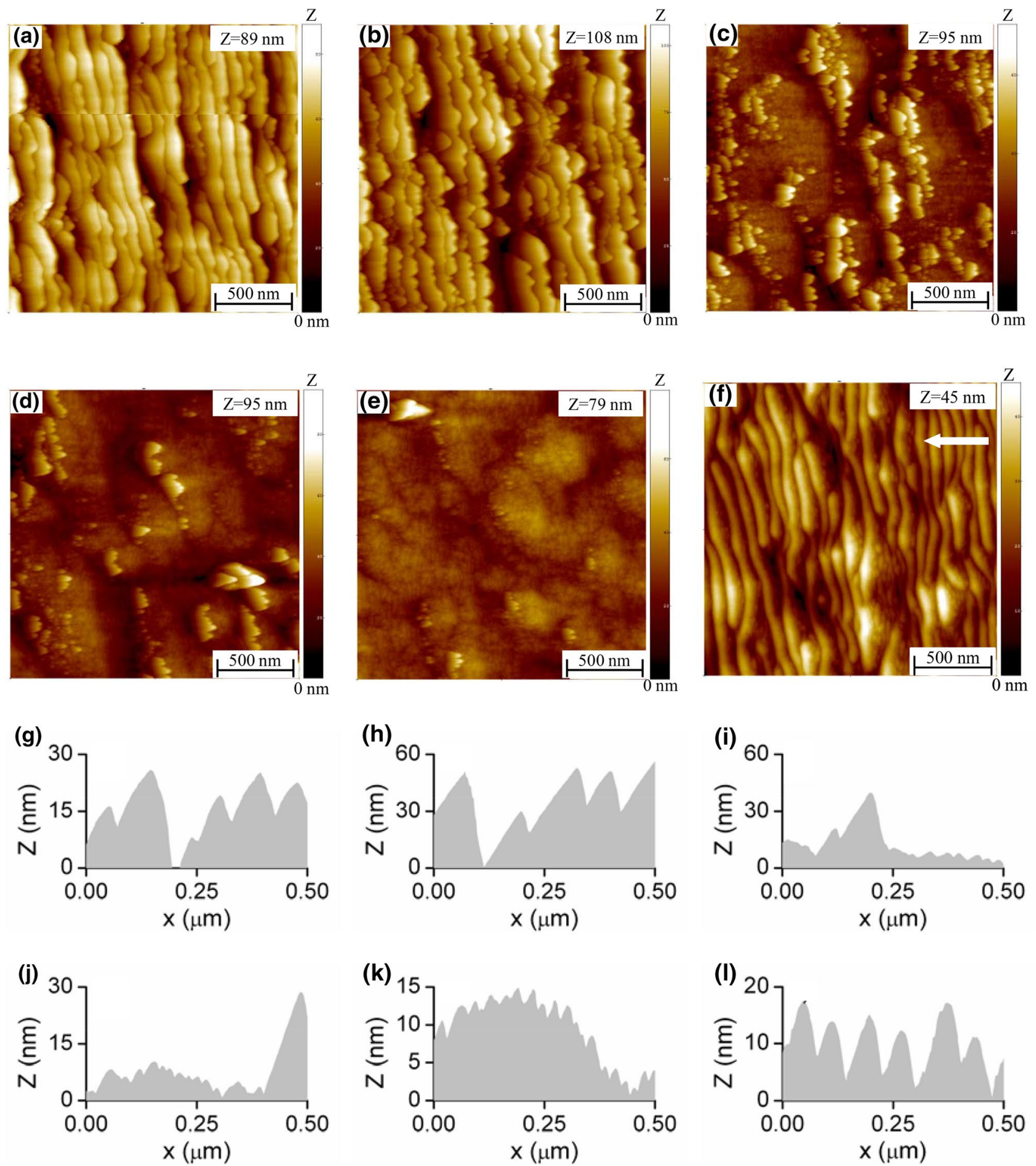

Fig. 8 Typical AFM images of pre-rippled $\mathrm{SiO}_{2}$ sample after sputtering with $\mathrm{Al}$ co-deposition at an incidence angle of $70^{\circ}$ at distances from the Al target of a $2 \mathrm{~mm}$, b $8 \mathrm{~mm}, \mathbf{c} 15 \mathrm{~mm}, \mathbf{d} 20 \mathrm{~mm}$, e $25 \mathrm{~mm}$, and $\mathbf{f}$ initial rippled substrate. The ion beam direction indicated by the white arrow in $\mathbf{f}$ is the same for each AFM image. $\mathbf{g}-\mathbf{l}$ Height profiles along lines parallel to the ion beam direction in $\mathbf{a}-\mathbf{f}$, respectively 


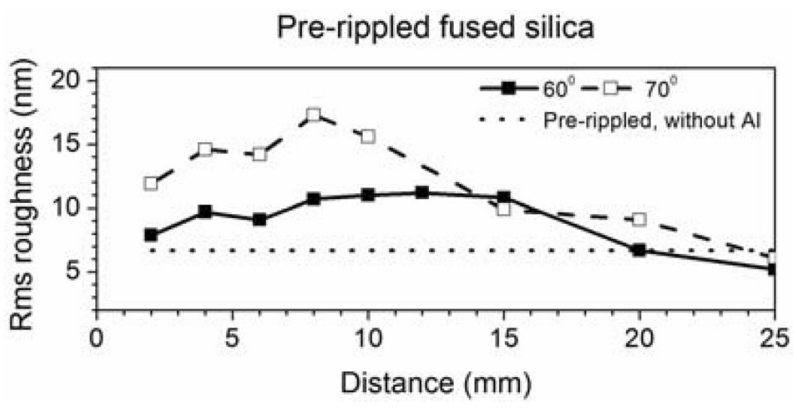

Fig. 9 Distance dependences of rms roughness of pre-rippled $\mathrm{SiO}_{2}$ treated with $400-\mathrm{eV} \mathrm{Ar}$ ions at incidence angles of $60^{\circ}$ and $70^{\circ}$. The horizontal dotted line indicates the roughness of the pre-rippled substrate

process of kinetic roughness, which is in agreement with previous investigations of $\mathrm{Si}$ [56] and $\mathrm{SiO}_{2}$ [6]. Initial prerippled surfaces showed great potential for morphological tuning and rms roughness enhancement.

\subsubsection{Comparison of results with previous investigations on the IBS of pre-patterned surfaces}

Considering potential optical applications, the quasi-blazed grating profile, formed on the pre-rippled $\mathrm{SiO}_{2}$ at the incidence angle of $70^{\circ}$, is a very promising result from the IBS of a compound with impurity co-deposition.

Harrison and Mark Bradley [62] have recently simulated the morphological evolution of a pre-patterned surface with IBS at an oblique incidence. The authors proposed a method of generating blazed diffraction gratings produced by ion bombardments of pre-patterned solid surfaces.

The results of our sputtering experiment both agreed and disagreed with those of the simulation by Harrison and Bradley. Although their simulation did not use exactly the same initial parameters as our sputtering experiment, both studies showed a very similar finding in the blazed profiles that can be formed on pre-patterned surfaces.

Our experiments further demonstrated the ability of codeposition during IBS to facilitate pattern generation and growth. In Harrison and Bradley's report [62], they emphasize that the amplitude of the initial pattern must be sufficiently large to obtain the blazed grating, indicating the opposite possibility that the initial amplitude may be too small to generate the blazed grating at the proposed oblique incidence. In our experiment, as shown in Fig. $8 \mathrm{f}-\mathrm{e}$, because of the insufficient original rms roughness of the pre-rippled surface, the treated surfaces tend to be smoother. In contrast, as shown in Fig. 8a, b, the Al co-deposition clearly improves the rms roughness of the blazed profile generated on a substrate with the same original rms roughness as those shown in Fig. 8e, f.

\subsection{Distance dependence of smooth Si morphology treated by oblique IBS with AI co-deposition}

In this subsection, the influence of $\mathrm{Al}$ co-deposition on the pattern evolution on Si surfaces is examined and compared to the previous observations of $\mathrm{Si}[11,12,31,32]$ and $\mathrm{SiO}_{2}$ presented above.

Figures 10 and 11 show the morphologies of the smooth $\mathrm{Si}$ after IBS with $\mathrm{Al}$ co-deposition at incidence angles of $60^{\circ}$ and $70^{\circ}$, respectively, and the figures show that the morphologies depended very little on the distance between the substrate and the $\mathrm{Al}$ wedge. The corresponding rms roughnesses and XPS analyses of $\mathrm{Al}$ and $\mathrm{Si}$ are shown in Fig. 12a-d. Table 1 compares the morphologies and rms roughnesses of the samples with and without Al co-deposition during IBS at incidence angles of both $60^{\circ}$ and $70^{\circ}$.

For Si located more than $25 \mathrm{~mm}$ from the edge of the $\mathrm{Al}$ wedge, regular ion-induced ripples were formed on the smooth $\mathrm{Si}$ at incidence angles of $60^{\circ}$ and $70^{\circ}$ as shown in Figs. 10f and 11f, which is in good agreement with previously reported sputtering of $\mathrm{Si}$ surfaces [11, 12].

With the introduction of $\mathrm{Al}$, the ion beam-induced ripples on the $\mathrm{Si}$ surface were coarsened and shortened, as shown in Figs. 10a-e and 11a-e and compared in Table 1. A similar coarsening and shortening has also been reported for the IBS of Si with Ag co-deposition [32]. During the IBS of Si with either $\mathrm{Au}$ or $\mathrm{Ag}$ co-deposition, there was no silicide formation [31, 32]. The coarsening of the patterns on the $\mathrm{Si}$ surface is due to the simultaneous Al deposition during IBS. Such coarsening is different from previously reported coarsening with increasing sputtering time $[7,9,12,63-65]$. Although some theoretical work has explained the coarsening based on numerical models [66, 67], a model and simulation that can accurately predict the coarsening due to the impurity co-deposition remains unavailable at this time.

In summary, with the introduction of $\mathrm{Al}$, the distance dependencies of the rms roughnesses of both smooth and pre-rippled $\mathrm{SiO}_{2}$ are pronounced. However, the distance dependencies of the morphology and roughness of smooth $\mathrm{Si}$ showed only a very slight correlation with the $\mathrm{Al}$ content. Before analyzing the nanostructures formed on the Si surface, we compared the chemical components deposited on the smooth $\mathrm{SiO}_{2}$ and $\mathrm{Si}$ by XPS measurements.

\subsection{Comparison of XPS analyses of smooth $\mathrm{SiO}_{2}$ and Si surfaces}

Figure 13a and $\mathrm{b}$ illustrate the distance dependence of the concentration of key chemical components analyzed by XPS on smooth $\mathrm{SiO}_{2}$ and $\mathrm{Si}$, respectively. Besides A12p, F1s and very little $\mathrm{Fe} 2 \mathrm{p}$ were also detected on both samples. Both $\mathrm{F}$ and $\mathrm{Fe}$ may have originated from the $\mathrm{Al}$ wedge and from the chamber walls of the IBS machine because of memory 

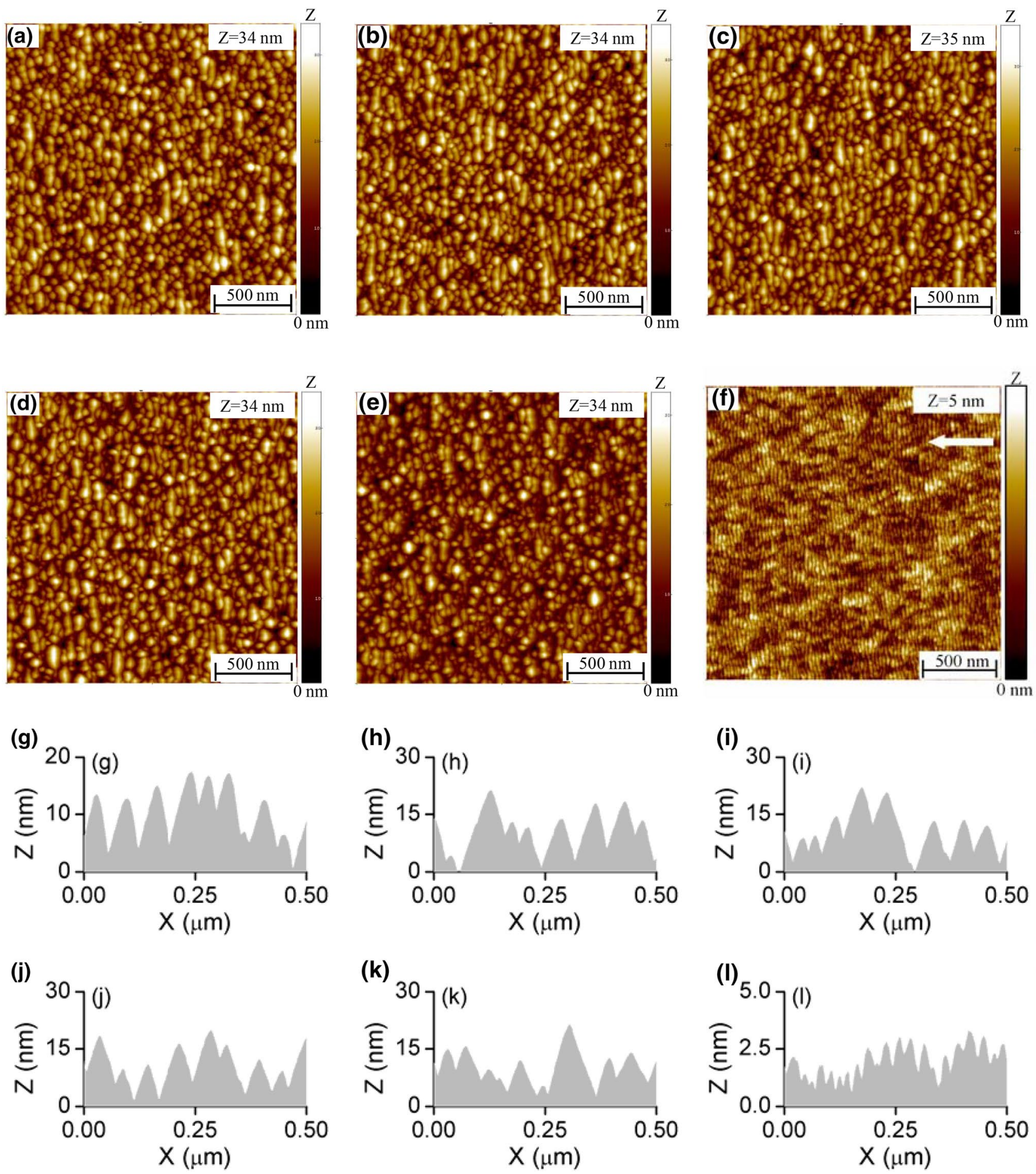

Fig. 10 Typical AFM images of smooth $\mathrm{Si}$ sample after sputtering with $\mathrm{Al}$ co-deposition at incidence angle of $60^{\circ}$ at distances from the Al target of a $4 \mathrm{~mm}$, b $8 \mathrm{~mm}$, c $10 \mathrm{~mm}$, d $15 \mathrm{~mm}$, e $25 \mathrm{~mm}$, and

effects from reactive ion beam etching processes. The concentrations of $\mathrm{Fe} 2 \mathrm{p}$ on both samples and that of $\mathrm{F} 1 \mathrm{~s}(\mathrm{CFx})$ on the smooth $\mathrm{Si}$ were too small to affect the formation of nanostructures. Those chemical components that showed f without $\mathrm{Al}$ co-deposition. The ion beam direction indicated by the white arrow in $\mathbf{f}$ is the same for each AFM image. $\mathbf{g}-\mathbf{l}$ Height profiles along lines parallel to the ion beam direction in $\mathbf{a}-\mathbf{f}$, respectively

concentrations that depended on the distance, such as Al2p and F1s (metal fluoride), were considered to originate from the $\mathrm{Al}$ wedge. The effect of Al2p and F1s (metal fluoride) 

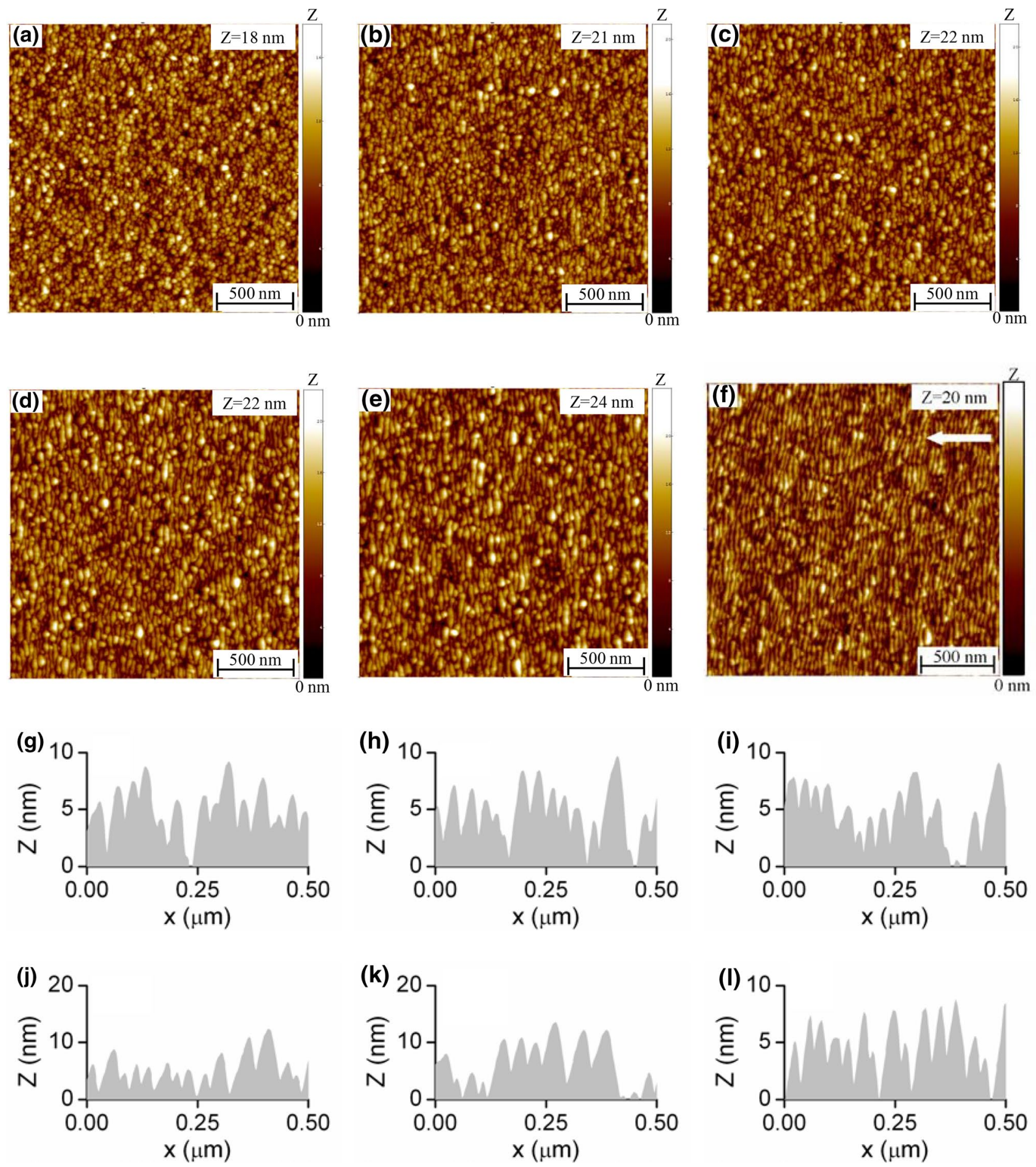

Fig. 11 Typical AFM images of smooth Si sample after sputtering with $\mathrm{Al}$ co-deposition at an incidence angle of $70^{\circ}$ at distances from the Al target of a $4 \mathrm{~mm}, \mathbf{b} 8 \mathrm{~mm}$, c $10 \mathrm{~mm}$, d $15 \mathrm{~mm}$, e $25 \mathrm{~mm}$, and f without $\mathrm{Al}$ co-deposition. The ion beam direction indicated by the white arrow in $\mathbf{f}$ is the same for each AFM image. $\mathbf{g}-\mathbf{l}$ Height profiles along lines parallel to the ion beam direction in $\mathbf{a}-\mathbf{f}$, respectively

components and the corresponding binding energy as determined by XPS. Both samples have been analyzed at a distance of $8 \mathrm{~mm}$ away from the $\mathrm{Al}$ wedge edge during sputtering.
To determine whether or not $\mathrm{Al}$ silicide formed on both

samples, Table 2 details the concentrations of key chemical upon nanostructure generation will be considered in the following subsection. 

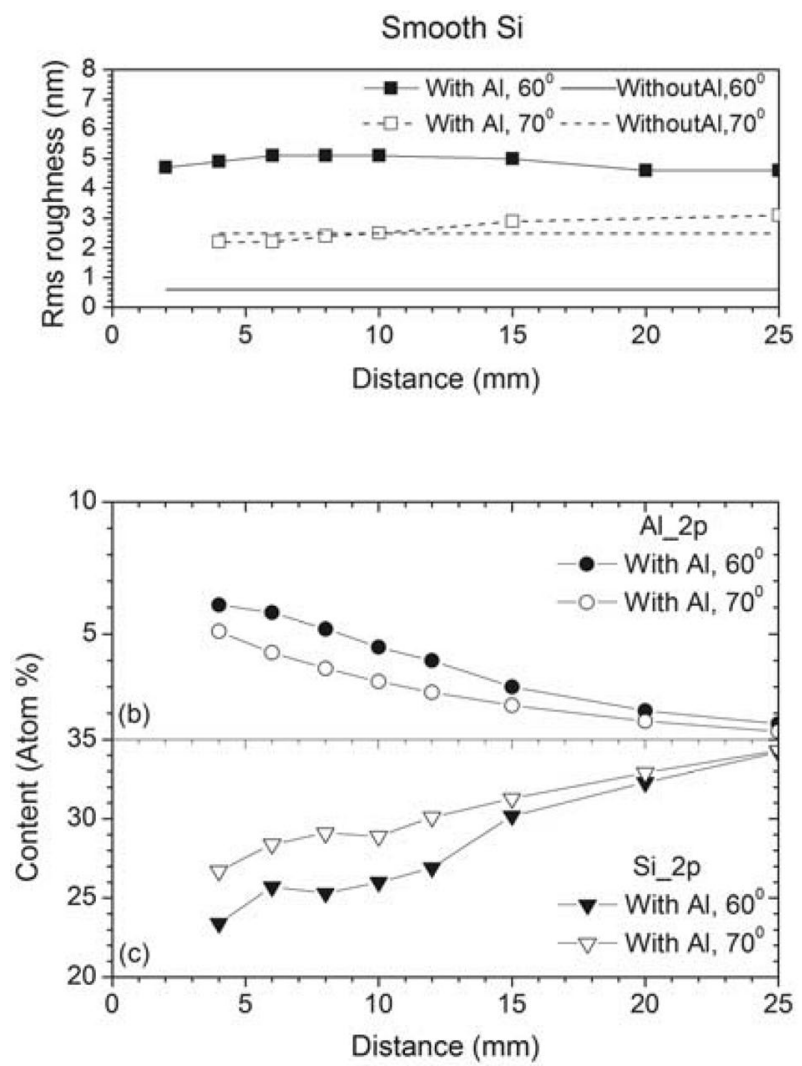

Fig. 12 Distance dependences of a rms roughness, b Al content, and c Si content of smooth $\mathrm{Si}$ at incidence angles of $60^{\circ}$ and $70^{\circ}$. The horizontal solid and dashed lines in a correspond to the roughnesses of the sputtered substrates without $\mathrm{Al}$ co-deposition at incidence angles of $60^{\circ}$ and $70^{\circ}$, respectively

For $\mathrm{SiO}_{2}, \mathrm{Al}$ exhibited only one single peak at the binding energy of $74.8 \mathrm{eV}$, which is $0.1-1.1 \mathrm{eV}$ higher than previously reported data for various $\mathrm{Al}_{2} \mathrm{O}_{3}$ modifications [68]. Hence the mixed oxyfluoride $\mathrm{AlO}_{\mathrm{x}} \mathrm{F}_{\mathrm{y}}$ was present, and the $\mathrm{Al}$ was partly bound to oxygen and fluorine. Absolutely no $\mathrm{Al}$ or $\mathrm{AlSi}$ was detected.

For $\mathrm{Si}, \mathrm{Al}$ clearly occurred in two states: one with a binding energy of $72.8 \mathrm{eV}$, and the other with a binding energy of $74.8 \mathrm{eV}$. The state of $\mathrm{Al}$ with the binding energy of $72.8 \mathrm{eV}$ may indicate AlSi. This compound has been reported to form during deposition of $\mathrm{Al}$ on $\mathrm{Si}$ at a base pressure of $10^{-7}$ Torr and a temperature of $550{ }^{\circ} \mathrm{C}$ [69]. However, our experiments were done at room temperature with background pressures of $10^{-5}-10^{-6} \mathrm{mbar}$, therefore, the formation of AlSi on Si is unlikely. In addition, the concentration of $\mathrm{Al}$ at $72.8 \mathrm{eV}$ is only $0.19 \%$, which is too low to affect the formation of nanostructures.

For the state of $\mathrm{Al}$ at the binding energy of $74.8 \mathrm{eV}$, according to Sitzmann [70], silicides of ignoble metals, such as $\mathrm{Al}$, are strongly attacked by oxidizing substances like $\mathrm{O}$, $\mathrm{H}_{2} \mathrm{O}$, and $\mathrm{F}$. The reaction enthalpy of the formation of $\mathrm{Al}_{2} \mathrm{O}_{3}$ or $\mathrm{AlF}_{3}$ is larger than that of $\mathrm{AlSi}$. Therefore, the compound at the binding energy of $74.8 \mathrm{eV}$ is considered to be more likely $\mathrm{AlO}_{\mathrm{x}} \mathrm{F}_{\mathrm{y}}$ than $\mathrm{Al}_{2} \mathrm{SiO}_{5}$.

As shown in Fig. 13a and b, because the concentration of a metal fluoride (ionic bonding of $\mathrm{F}$ ) is distance-dependent, the metal fluorides with the binding energies of approximately $685 \mathrm{eV}$ on both samples in Table 2 should come from the $\mathrm{Al}$ wedge. The formation of $\mathrm{AlF}_{3}$ and $\mathrm{Al}_{2} \mathrm{O}_{3}$ immobilizes the deposited disperse $\mathrm{Al} . \mathrm{Al}_{2} \mathrm{O}_{3}$ and $\mathrm{AlF}_{3}$ are not able to form AlSi because high energy is needed to reduce the $\mathrm{Al}$ from the stable state +3 in an oxide, fluoride, or mixed deposit.

This XPS analysis clearly demonstrates that no AlSi was formed on either the $\mathrm{SiO}_{2}$ or the $\mathrm{Si}$ surface. Only $\mathrm{AlO}_{\mathrm{x}} \mathrm{F}_{\mathrm{y}}$ (or less likely $\mathrm{Al}_{2} \mathrm{SiO}_{5}$ ) compounds were detected, with a higher concentration on $\mathrm{SiO}_{2}$ (as shown in Figs. 6b and 12b) than on $\mathrm{Si}$. The higher concentration of $\mathrm{AlO}_{\mathrm{x}} \mathrm{F}_{\mathrm{y}}$ on $\mathrm{SiO}_{2}$ results from the oxygen provided by the $\mathrm{SiO}_{2}$.

\subsection{Discussion}

We have shown the distance dependence of the morphology and rms roughness of $\mathrm{SiO}_{2}$ and $\mathrm{Si}$ surfaces sputtered at oblique incidence angles with $\mathrm{Al}$ co-deposition. At positions sufficiently far from the $\mathrm{Al}$ wedge, the IBS experiments show that ripples were generated on both $\mathrm{SiO}_{2}$ and $\mathrm{Si}$ by the Ar ion beam sputtering without $\mathrm{Al}$ co-deposition. This is in accordance with earlier studies [5, 7]. The surface evolution in these cases, at least in the low-fluence regime, can be described following the classical BH model [61]. Therefore, from the results of our experiments, sputtering based on the $\mathrm{BH}$ model is considered one important mechanism of
Table 1 Morphologies of smooth $\mathrm{Si}$ with incidence angles of $60^{\circ}$ and $70^{\circ}$

\begin{tabular}{llllll}
\hline & I without Al & & \multicolumn{2}{l}{ II with Al } \\
\cline { 2 - 3 } \cline { 5 - 6 } & $60^{\circ}$ & $70^{\circ}$ & & $60^{\circ}$ & $70^{\circ}$ \\
\hline Morphology & Self-organized ripple & & & \multicolumn{2}{l}{ Short and coarsened ripple and dots } \\
Wavelength (nm) & 26 & 36 & & $40-65$ & $30-65$ \\
Amplitude (nm) & $\sim 1$ & $\sim 5$ & & $5-10$ & $3-5$ \\
rms roughness (nm) & 0.6 & 2.5 & & $4.7-5.1$ & $2.2-3.1$ \\
$\begin{array}{l}\text { Comparison of rms } \\
\text { roughness }\end{array}$ & $\operatorname{rms}_{\mathrm{I}}\left(60^{\circ}\right)<\mathrm{rms}_{\mathrm{I}}\left(70^{\circ}\right)$ & & & $\operatorname{rms}_{\mathrm{II}}\left(60^{\circ}\right)>\mathrm{rms}_{\mathrm{II}}\left(70^{\circ}\right)$ & \\
\hline
\end{tabular}



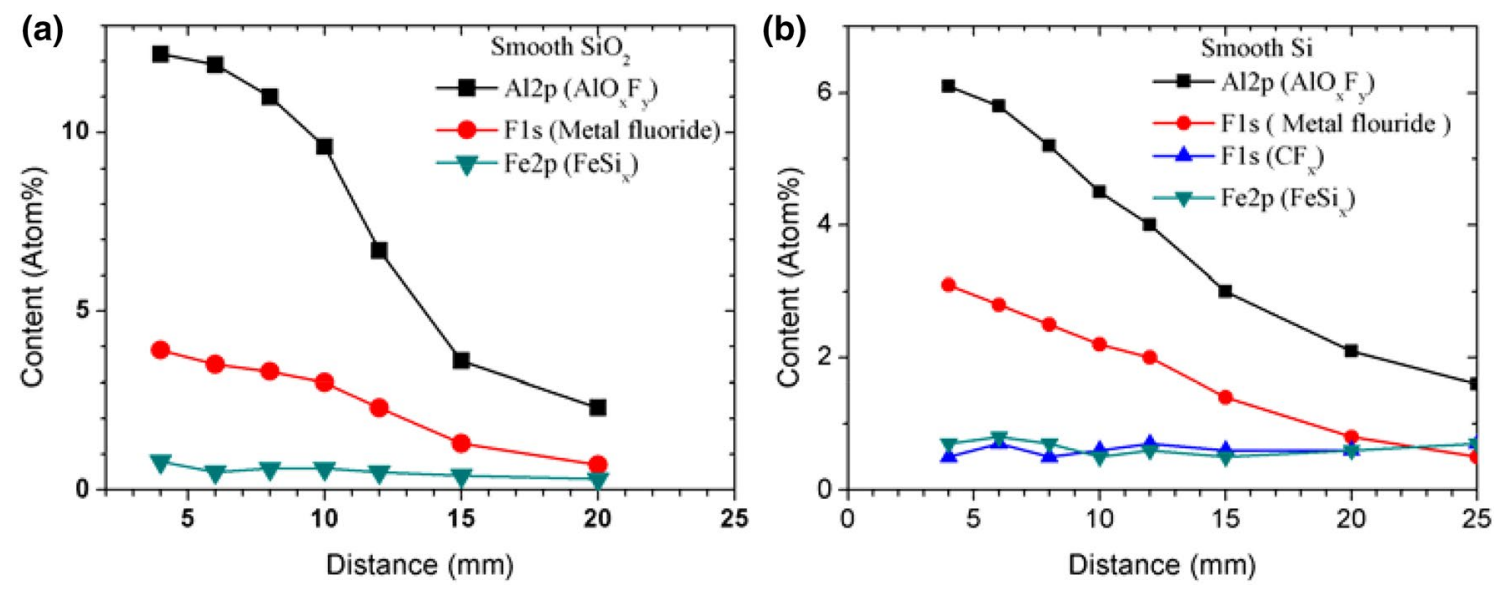

Fig. 13 Distance dependences of the content of chemical components on $\mathbf{a}$ smooth $\mathrm{SiO}_{2}$ and $\mathbf{b}$ smooth $\mathrm{Si}$ surfaces

Table 2 Concentrations of chemical components on $\mathrm{SiO}_{2}$ and $\mathrm{Si}$

\begin{tabular}{lll}
\hline $\begin{array}{l}\text { Substrate (8 mm away from } \\
\text { the Al wedge edge) }\end{array}$ & $\begin{array}{l}\text { Al2p binding energy (eV); concentra- } \\
\text { tion (At.-\%); possible compound(s) }\end{array}$ & $\begin{array}{l}\text { F1s binding energy (eV); } \\
\text { concentration (At.-\%); possible } \\
\text { compound(s) }\end{array}$ \\
\hline $\mathrm{SiO}_{2}$ & $74.8,11.01$ & $685.5,3.28$ \\
& AlOxFy & $\begin{array}{l}\text { Metal fluoride } \\
\mathrm{Si}\end{array}$ \\
$72.8,0.19$ & $685.7,2.48$ \\
& $\mathrm{Al}, \mathrm{AlFe}, \mathrm{AlSi}$ & Metal fluoride \\
& $74.8,4.97$ & $689.3,0.53$ \\
& AlOxFy & Fluorocarbons \\
\hline
\end{tabular}

pattern formation, which is similar to the findings of other investigations.

The XPS analyses clearly showed no AlSi; however, these analyses indicated the formation of $\mathrm{AlO}_{\mathrm{x}} \mathrm{F}_{\mathrm{y}}$ compounds. This chemical product is different from the metallic silicides previously reported from investigations into IBS of $\mathrm{Si}$ with metal co-deposition. Our findings are unique because the chemical products of not metallic silicides, but $\mathrm{AlO}_{\mathrm{x}} \mathrm{F}_{\mathrm{y}}$ should originate in the co-deposited impurity of $\mathrm{Al}$, in conjunction with the general ion beam sputtering. In the following, an alternative explanation of the observed modification of the surface morphology and simultaneous Al co-deposition is discussed based on the sputtering yields and erosion velocities of $\mathrm{AlO}_{\mathrm{x}} \mathrm{F}_{\mathrm{y}}, \mathrm{SiO}_{2}$, and $\mathrm{Si}$, along with sputtering geometry and initial rms roughness of the surfaces. This explanation is premised on the reasonable assumption that the micro-masking of both $\mathrm{SiO}_{2}$ and $\mathrm{Si}$ occurs because of the differences in the sputtering yields or erosion velocities.

For a more detailed discussion of the micro-masking effect, the sputter yields or etch rates of the different materials $\left(\mathrm{SiO}_{2}, \mathrm{Si}, \mathrm{Al}, \mathrm{AlO}_{\mathrm{x}} \mathrm{F}_{\mathrm{y}}\right)$ would be required. However, these data are not easy to obtain. Simulations programs such as SRIM [71] or, better, TRIMP.SP [72] can be used, but these require the correct input parameters (e.g., surface binding energy). For the compound $\mathrm{AlO}_{\mathrm{x}} \mathrm{F}_{\mathrm{y}}$ these parameters are not known. Therefore, approximate calculations were conducted for 400-eV Ar ions hitting a $\mathrm{SiO}_{2}, \mathrm{Si}, \mathrm{Al}$, or $\mathrm{Al}_{2} \mathrm{O}_{3}$ surface using TRIM.SP, with the potentials and free parameters that have been suggested by Eckstein [73]. The surface binding energies for $\mathrm{Si}(4.7 \mathrm{eV})$ and $\mathrm{Al}(3.36 \mathrm{eV})$ are well established [73]. However, the surface binding energies of both oxide compounds remain difficult to obtain. In this discussion, we use the surface binding energy values estimated from experimentally estimated sputtering yields that were fitted with an analytical expression for the sputtering yield that was derived by Sigmund [74]. Following the weighted mole fraction approach [74], the surface binding energies of $10.0 \mathrm{eV}$ and $4.1 \mathrm{eV}$ were calculated for $\mathrm{Al}_{2} \mathrm{O}_{3}$ and $\mathrm{SiO}_{2}$, respectively. From the resulting sputtering yields (Fig. 14a), the erosion velocities (Fig. 14b) were calculated for an ion current density of $200 \mu \mathrm{A} / \mathrm{cm}^{2}$, based on the atomic densities of the materials.

As expected from the surface binding energy values, $\mathrm{Al}_{2} \mathrm{O}_{3}$ exhibited the lowest sputtering yield, and $\mathrm{Al}$ exhibited the highest. Different trends were demonstrated in the erosion velocities, which are responsible for the local evolution of the surface. Because of the high atomic density of $\mathrm{Al}$, the erosion velocities of $\mathrm{Si}, \mathrm{Al}$, and $\mathrm{Al}_{2} \mathrm{O}_{3}$ were more or less the same, and $\mathrm{SiO}_{2}$ displayed the highest erosion velocities. 
Fig. 14 a Sputtering yields and b erosion velocities of $\mathrm{SiO}_{2}$, $\mathrm{Si}, \mathrm{Al}$, and $\mathrm{Al}_{2} \mathrm{O}_{3}$ as a function of the ion incidence angle, as simulated in the Monte Carlo program TRIM.SP with $400 \mathrm{eV}-\mathrm{Ar}^{+}$irradiation at $200 \mu \mathrm{A} / \mathrm{cm}^{2}$
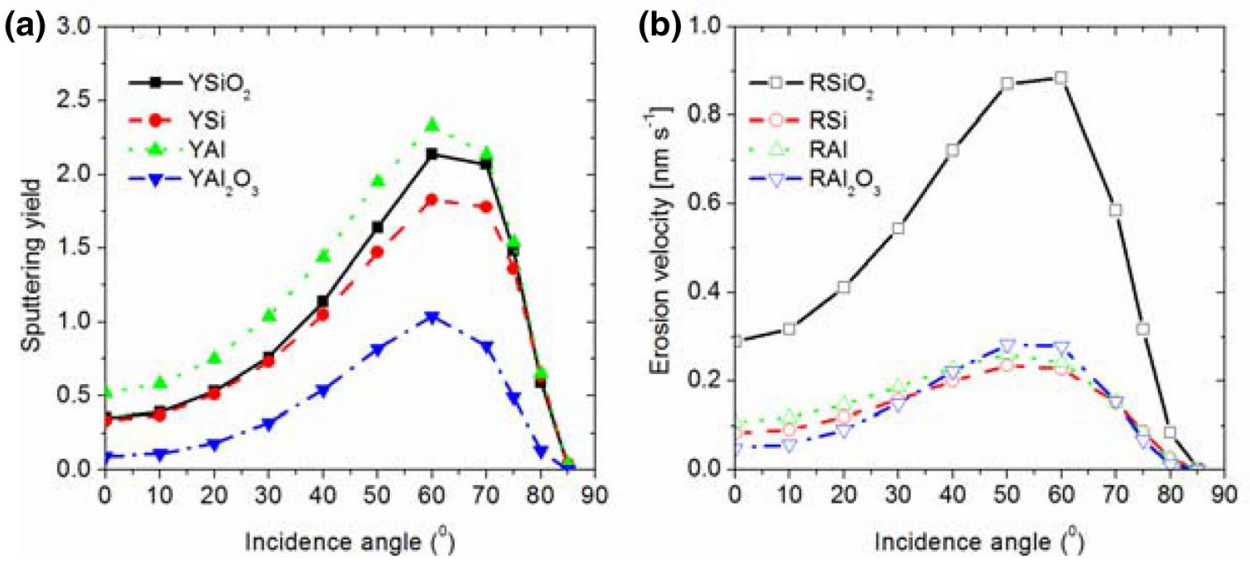

A similarly high etching resistance as that of $\mathrm{Al}_{2} \mathrm{O}_{3}$ can be expected for the highly nonvolatile $\mathrm{AlF}_{3}$. Therefore, a strong $\mathrm{SiO}_{2}$ micro-masking effect can be reasonably assumed to be caused by a mixed oxyfluoride, $\mathrm{AlO}_{\mathrm{x}} \mathrm{F}_{\mathrm{y}}$. Depending on the sputter conditions, the simultaneous $\mathrm{Al}$ co-deposition can be expected to enhance structural heights (e.g., rms roughness), especially in areas near the Al wedge. For $\mathrm{Si}$, the micromasking effect is expected to be less pronounced, if it occurs at all. Indeed, this is confirmed by the results presented for Al co-deposition on Si.

In addition, the sputtering geometry and the roughness of the substrates play an important role in the morphological evolution of the surface, as can be clearly observed by comparing Figs. 7 and 8. In Fig. 7, the pre-pattern was aligned parallel to the ion beam (coming from the right) as well as to the Al particle flux direction (coming from the left). Therefore, no shadowing occured, resulting in uniform coverage with $\mathrm{Al}$ (or, better, $\mathrm{AlO}_{\mathrm{x}} \mathrm{F}_{\mathrm{y}}$ ) near the $\mathrm{Al}$ wedge, where the Al flux was sufficiently high; this produced an isotropic pattern on the surface (Fig. 7a, b). Further away from the wedge (Fig. 7c), the Al concentration decreased and only some regions were masked, precluding the formation of a uniform or isotropic roughness. Even further away, the topography evolution was almost unaffected by the $\mathrm{Al}$ and a superimposed ripple pattern developed due to the ion beam erosion of the initially parallel aligned pre-pattern, in accordance with the observations reported in [6].

These results contrast with those shown in Fig. 8, where the pre-rippled surface is aligned perpendicular to the ion beam and to the $\mathrm{Al}$ particle flux direction. In this arrangement, shadowing caused the $\mathrm{Al}$ to be predominantly deposited on the sides of the ripples facing the $\mathrm{Al}$ wedge (downstream from the ion beam), whereas the face pointing to the ion beam (on the upstream side) received much less Al. Therefore, the upstream side, as well as the valleys between the ripple ridges were eroded faster compared to the downstream side, which was sputtered with greater amounts of $\mathrm{Al}$ or $\mathrm{AlO}_{\mathrm{x}} \mathrm{F}_{\mathrm{y}}$. With increasing distance from the $\mathrm{Al}$ wedge,

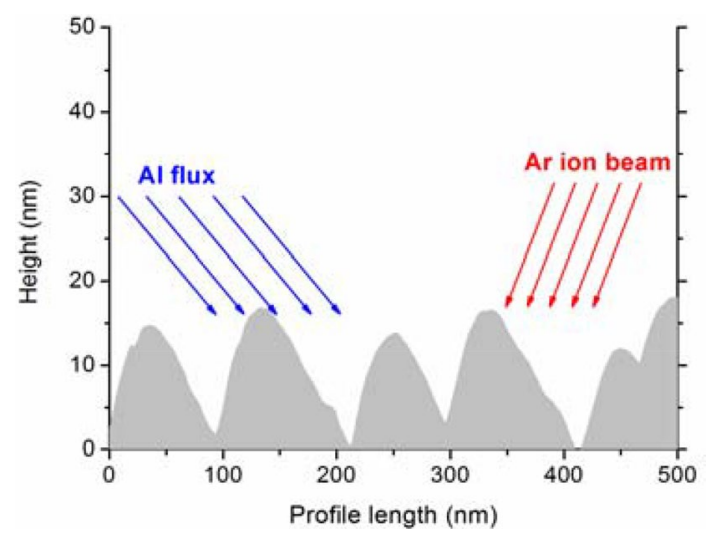

Fig. 15 Schematic diagram of the shadow effect of the pre-rippled surface on which the initial ripples were perpendicular to the ion beam and $\mathrm{Al}$ particle flux direction

the $\mathrm{Al}$ concentration decreased further (Fig. 8c, d), and only some of the downstream faces received sufficient $\mathrm{Al}$ to show a micro-masking effect. At large distances, the topography was scarcely influenced by the $\mathrm{Al}$, and the initially present ripple pattern followed an evolution typical of these ion beam conditions, except for additional roughness wavelength components originating from the pre-pattern; this result is also supported by [6].

These results are illustrated in Fig. 15, where a typical surface profile of the pre-pattern, together with the incidence directions of the $\mathrm{Al}$ flux and the $\mathrm{Ar}$ ion beam are shown, drawn to scale. The sputtering geometry in Fig. 8 corresponds to that in which the Ar ions come from the right at an incidence angle of $70^{\circ}$ (corresponding to $20^{\circ}$ to the sample surface) and the $\mathrm{Al}$ comes from the left at an incidence angle of $0^{\circ}$ to the normal of the wedge surface (due to the $20^{\circ}$ wedge angle) with a cosine distribution around this angle. If we consider a representative emission angle of $30^{\circ}$ for the $\mathrm{Al}$ atoms from the normal of the wedge, then the angle to the substrate surface is also $10^{\circ}$ (i.e., $80^{\circ}$ with respect to the $\mathrm{SiO}_{2}$ surface normal), resulting in the geometrical situation 
shown in the figure, where the effect of shadowing is clearly evident.

With the ion beam erosion of the smooth Si surface, the pattern was less affected by the $\mathrm{Al}$ co-deposition. This can be explained by the lower concentration of $\mathrm{AlO}_{\mathrm{x}} \mathrm{F}_{\mathrm{y}}\left(\right.$ or $\left.\mathrm{Al}_{2} \mathrm{SiO}_{5}\right)$ on $\mathrm{Si}$ compared to $\mathrm{SiO}_{2}$ (Figs. 6 and 12, respectively). The differences in the erosion velocities of $\mathrm{Si}$ and $\mathrm{Al}$ or $\mathrm{Al}$ compounds are rather insignificant, as apparent from Fig. 14b.

Because the calculations shown in Fig. 14 are an approximation, higher $\mathrm{Al}$ concentrations and different (albeit small) erosion velocities may result in differences in the surface evolution with and without Al co-depeosition. This may be one reason for which the $\mathrm{Si}$ experiments conducted at incidence angles of $60^{\circ}$ produced a more pronounced change in topography compared to the surface sputtered without $\mathrm{Al}$ co-deposition (Fig. 10f).

At present, there is no model that can predict all nanostructure formation and evolution induced by IBS on monoelemental materials. The $\mathrm{SiO}_{2}$ case should be more complex than a mono-elemental material such as $\mathrm{Si}$. In this paper, we focused on pattern formation on $\mathrm{SiO}_{2}$ with simultaneous $\mathrm{Al}$ co-deposition in comparison with $\mathrm{Si}$. We hope this preliminary comparison of $\mathrm{Si}$ and $\mathrm{SiO}_{2}$ will stimulate further investigations on the formation of IBS-induced nanostructures.

\section{Conclusions}

To conclude, we have investigated the IBS of $\mathrm{SiO}_{2}$ with simultaneous Al co-deposition. The investigation extends the investigations of IBS with impurity co-deposition from a smooth mono-elemental material $(\mathrm{Si})$ to a pre-rippled binary compound $\left(\mathrm{SiO}_{2}\right)$, from normal to oblique incidence angles, and from the $\mathrm{Si}$ products of $\mathrm{Fe}, \mathrm{Mo}$, etc, to $\mathrm{AlO}_{\mathrm{x}} \mathrm{F}_{\mathrm{y}}$ products.

The pattern generation and evolution in such a sputtering and co-deposition configuration are attributed to the interplay between ion beam sputtering of $\mathrm{Ar}^{+}$ion driven by a $\mathrm{BH}$ mechanism and the directional deposition of $\mathrm{Al}$ atoms. Amplified sputtering yields and erosion velocities are realized by $\mathrm{AlO}_{\mathrm{x}} \mathrm{F}_{\mathrm{y}}$ chemical products during IBS with concurrent $\mathrm{Al}$ deposition, and the $\mathrm{AlO}_{\mathrm{x}} \mathrm{F}_{\mathrm{y}}$ products function as micro-masking that significantly enhance the rms roughness of the surface morphology.

In the region where the rms roughness increased with increasing $\mathrm{Al}$ content, the coupling effect of the impurity co-deposition and the initial pre-rippling of the surface significantly roughens the morphology and enriches the pattern type, such that concurrent impurity deposition is demonstrated to improve the rms roughness of a smooth surface during IBS. The rms roughness of a surface can be further improved by changing the initial substrate from a smooth to a pre-rippled surface. Furthermore, 2D nanostructures and blazed nanograting have been found to form on pre-rippled $\mathrm{SiO}_{2}$ surfaces, and these patterns offer significant potential in optical applications.

To understand the formation and development mechanisms of nanostructures and to tailor diverse nanopatterns in a deterministic way, further experimental work will focus on the impurity selection (such as using impurities that are either stable or easily oxidized), time evolution, geometric configurations of the sputtering and co-deposition system, and surfaces consisting of other binary compounds. A more comprehensive simulation is needed to predict quantitatively the results obtained by IBS with concurrent impurity codeposition on pre-rippled surfaces.

In the paper, we confined most of our focus upon the investigation of smooth and pre-rippled $\mathrm{SiO}_{2}$ surfaces. Some observations on smooth Si surface have been demonstrated in this paper. The investigation on smooth $\mathrm{Si}$ will be conducted in detail elsewhere.

The results reported here are not only helpful to understand the formation of nanopatterns induced by IBS with simultaneous impurity co-deposition, but are also of technological relevance to identify quantitatively the effects of non-intentional process contamination on the morphologies and rms roughnesses of optical surfaces during ion beamassisted etching techniques. Low-energy IBS is a powerful and unique tool that can be used to prepare nanostructures in both destructive and constructive approaches [75]. We believe that the sputtering and co-deposition system investigated in this paper, also known as a surfactant sputtering system, integrates destructive (sputtering) and constructive (deposition) approaches to nanostructuring and can facilitate sputtering-deposition experiments that generate novel and versatile nanostructures with many potential applications.

Acknowledgements This work is supported by the Deutsche Forschungsgemeinschaft (Grant No. FOR 845). The authors thank colleagues at IOM for technical support. Ying Liu would like to thank the financial support from China Scholarship Council (CSC No. 201306345004) for her work at IOM. Ying Liu greatly appreciates Dr. Axel Schindler of IOM for his kind recommendation upon her visit research. Ying Liu is grateful to the National Natural Science Foundation of China and the Key Science and Technology Program of Anhui Province, China for their supports on data analyses and manuscript revision through Grant Nos. 11675169 and 131015195 , respectively. The authors would like to thank for a reviewer's valuable comments to improve the manuscript.

Open Access This article is distributed under the terms of the Creative Commons Attribution 4.0 International License (http://creativecommons.org/licenses/by/4.0/), which permits unrestricted use, distribution, and reproduction in any medium, provided you give appropriate credit to the original author(s) and the source, provide a link to the Creative Commons license, and indicate if changes were made. 


\section{References}

1. E. Chason, T.M. Mayer, Low energy ion bombardment induced roughening and smoothing of $\mathrm{SiO}_{2}$ surfaces. Appl. Phys. Lett. 62, 363 (1993)

2. T.M. Mayer, E. Chason, A.J. Howard, Roughening instability and ion induced viscous relaxation of $\mathrm{SiO}_{2}$ surfaces. J. Appl. Phys. 76, 1633 (1994)

3. D. Flamm, F. Frost, D. Hirsch, Evolution of surface topography of fused silica by ion beam sputtering. Appl. Surf. Sci. 179, 95 (2001)

4. A. Toma, F.B. Mongeot, R. Buzio, G. Firpo, S.R. Bhattacharyya, C. Boragno, U. Valbusa, Ion beam erosion of amorphous materials: evolution of surface morphology. Nucl. Instr. Meth. B 230, $551(2005)$

5. A. Keller, S. Facsko, W. Möller, The morphology of amorphous $\mathrm{SiO}_{2}$ surfaces during low energy ion sputtering. J. Phys. Condens. Matter. 21, 495305 (2009)

6. J. Völlner, B. Ziberi, F. Frost, B. Rauschenbach, Topography evolution mechanism on fused silica during low-energy ion beam sputtering. J. Appl. Phys. 109, 043501 (2011)

7. M. Teichmann, J. Lorbeer, F. Frost, B. Rauschenbach, Ripple coarsening on ion beam-eroded surfaces. Nanoscale Res. Lett. 9, $439(2014)$

8. B. Ziberi, F. Frost, Th. Höche, B. Rauschenbach, Ripple pattern formation on silicon surfaces by low-energy ion-beam erosion: Experiment and theory. Phys. Rev. B 72, 235310 (2005)

9. K. Zhang, F. Rotter, M. Uhrmacher, C. Ronning, H. Hofsäss, J. Krauser, Pattern formation of Si surfaces by low-energy sputter erosion. Surf. Coat. Technol. 201, 8299 (2007)

10. B. Ziberi, M. Cornejo, F. Frost, B. Rauschenbach, Highly ordered nanopatterns on Ge and Si surfaces by ion beam sputtering. J. Phys. Condens. Matter. 21, 224003 (2009)

11. K. Zhang, H. Hofsäss, F. Rottera, M. Uhrmachera, C. Ronninga, J. Krauser, Morphology of Si surfaces sputter-eroded by lowenergy Xe-ions at glancing incident angle. Surf. Coat. Technol. 203, 2395 (2009)

12. M. Engler, S. Macko, F. Frost, T. Michley, Evolution of ion beam induced patterns on Si(001). Phys. Rev. B 89, 245412 (2014)

13. M. Teichmann, J. Lorbeer, B. Ziberi, F. Frost, B. Rauschenbach, Pattern formation on Ge by low energy ion beam erosion. New J. Phys. 15, 103029 (2013)

14. S. Rusponi, C. Boragno, U. Valbusa, Ripple Structure on $\operatorname{Ag}(110)$ Surface induced by ion sputtering. Phy. Rev. Lett. 78, $2795(1997)$

15. S. Facsko, T. Dekorsy, C. Koerdt, C. Trappe, H. Kurz, A. Vogt, H.L. Hartnagel, Formation of ordered nanoscale semiconductor dots by ion sputtering. Science 285, 1551 (1999)

16. F. Frost, A. Schindler, F. Bigl, Roughness evolution of ion sputtered rotating InP surfaces: pattern formation and scaling laws. Phys. Rev. Lett. 85, 4116 (2000)

17. F. Frost, R. Fechner, B. Ziberi, D. Flamn, A. Schindler, Large area smoothing of optical surfaces by low-energy ion beams. Thin Solid Films 459, 100 (2004)

18. F. Frost, B. Ziberi, A. Schindler, B. Rauschenbach, Surface engineering with ion beams: from self-organized nanostructures to ultra-smooth surfaces. Appl. Phys. A 91, 551 (2008)

19. F. Frost, R. Fechner, B. Ziberi, J. Völlner, D. Flamm, A. Schindler, Large area smoothing of surfaces by ion bombardment: fundamentals and applications. J. Phys. Condens. Matter. 21, 224026 (2009)

20. G. Ozaydin, A.S. Özcan, Y. Wang, K.F. Ludwig, H. Zhou, R.L. Headrick, D.P. Siddons, Real-time X-ray studies of Mo-seeded Si nanodot formation during ion bombardment. Appl. Phys. Lett. 87, $163104(2005)$

21. G. Ozaydin-Ince, K.F. Ludwig Jr., In situ X-ray studies of native and Mo-seeded surface nanostructuring during ion bombardment of Si(100). J. Phys. Condens. Matter. 21, 224008 (2009)

22. S. Macko, F. Frost, B. Ziberi, D.F. Förster, T. Michely, Is keV ioninduced pattern formation on $\mathrm{Si}(001)$ caused by metal impurities? Nanotechnology 21, 085301 (2010)

23. M. Cornejo, B. Ziberi, C. Meinecke, D. Hirsch, J.W. Gerlach, T. Höche, F. Frost, B. Rauschenbach, Self-organized patterning on $\mathrm{Si}(001)$ by ion sputtering with simultaneous metal incorporation. Appl. Phys. A 102, 593 (2011)

24. M. Cornejo, B. Ziberi, C. Meinecke, F. Frost, Formation of two ripple modes on $\mathrm{Si}$ by ion erosion with simultaneous Fe incorporation. Appl. Surf. Sci. 257, 8659 (2011)

25. S. Macko, F. Frost, M. Engler, D. Hirsch, T. Höche, J. Grenzer, T. Michely, Phenomenology of iron-assisted ion beam pattern formation on Si(001). New J. Phys. 13, 073017 (2011)

26. J. Zhou, M. Hildebrandt, M. Lu, J. Self-organized antireflecting nano-cone arrays on Si (100) induced by ion bombardment. J. Appl. Phys. 109, 053513 (2011)

27. S. Macko, J. Grenzer, F. Frost, M. Engler, D. Hirsch, M. Fritzsche, A. Mücklich, T. Michely, Iron-assisted ion beam patterning of $\mathrm{Si}(001)$ in the crystalline regime. New J. Phys. 14, 073003 (2012)

28. A. Redondo-Cubero, R. Gago, F.J. Palomares, A. Mücklich, M. Vinnichenko, L. Vázquez, Nanopatterning dynamics on Si(100) during oblique $40-\mathrm{keV} \mathrm{Ar}^{+}$erosion with metal codeposition: Morphological and compositional correlation. Phys. Rev. B 86, 085436 (2012)

29. M. Engler, F. Frost, S. Müller, S. Macko, M. Will, R. Feder, D. Spemann, R. Hübner, S. Facsko, T. Michely, Silicide induced ion beam patterning of $\mathrm{Si}(001)$. Nanotechnology 25, 115303 (2014)

30. B. Khanbabaee, D. Lützenkirchen-Hecht, R. Hübner, J. Grenzer, S. Facsko, U. Pietsch, Near surface silicide formation after offnormal Fe-implantation of Si(001) surfaces. J. Appl. Phys. 116, 024301 (2014)

31. B. Moon, S. Yoo, J.-S. Kim, S.J. Kang, J. Muñoz-García, R. Cuerno, Ion-beam nanopatterning of silicon surfaces under codeposition of non-silicide-forming impurities. Phys. Rev. B 93, 115430 (2016)

32. H. Hofsäss, K. Zhang, Surfactant sputtering. Appl. Phys. A 92, $517(2008)$

33. H. Hofsäss, K. Zhang, Fundamentals of surfactant sputtering. Nucl. Instrum. Methods B 267, 2731 (2009)

34. K. Zhang, M. Brötzmann, H. Hofsäss, Surfactant-driven selforganized surface patterns by ion beam erosion. New J. Phys. 13, 013033 (2011)

35. K. Zhang, M. Brötzmann, H. Hofsäss, Sharp transition from ripple patterns to a flat surface for ion beam erosion of $\mathrm{Si}$ with simultaneous co-deposition of iron. AIP Adv. 2, 032123 (2012)

36. H. Hofsäss, K. Zhang, H.G. Gehrke, C. Brüsewitz, Propagation of ripple patterns on Si during ion bombardment. Phys. Rev. B 88, 075426 (2013)

37. H. Hofsäss, K. Zhang, A. Pape, O. Bobes, M. Brötzmann, The role of phase separation for self-organized surface pattern formation by ion beam erosion and metal atom co-deposition. Appl. Phys. A 111, 653 (2013)

38. K. Zhang, O. Bobes, H. Hofsäss, Designing self-organized nanopatterns on Si by ion irradiation and metal co-deposition. Nanotechnology 25, 085301 (2014)

39. S.K. Vayalil, A. Gupta, S.V. Roth, Study of pattern transition in nanopatterned $\mathrm{Si}(100)$ produced by impurity-assisted low-energy ion-beam erosion. Appl. Phys. A 123, 225 (2017)

40. J. Zhou, M. Lu, Mechanism of Fe impurity motivated ion-nanopatterning of Si (100) surfaces. Phys. Rev. B 82, 125404 (2010) 
41. R.M. Bradley, Theory of nanodot and sputter cone arrays produced by ion sputtering with concurrent deposition of impurities. Phys. Rev. B 83, 195410 (2011)

42. R.M. Bradley, Producing ripple topographies by ion bombardment with codeposition of impurities: a curvature-dependent sputter yield is not required. Phys. Rev. B 85, 115419 (2012)

43. R.M. Bradley, Nanoscale patterns produced by ion erosion of a solid with codeposition of impurities: The crucial effect of compound formation. Phys. Rev. B 87, 205408 (2013)

44. R.M. Bradley, Morphological transitions in nanoscale patterns produced by concurrent ion sputtering and impurity co-deposition. J. Appl. Phys. 119, 134305 (2016)

45. S.A. Norris, Ion-assisted phase separation in compound films: An alternate route to ordered nanostructures. J. Appl. Phys. 114, 204303 (2013)

46. R. Kree, T. Yasseri, A.K. Hartmann, Surfactant sputtering: Theory of a new method of surface nanostructuring by ion beams. Nucl. Instrum. Methods B 267, 1403 (2009)

47. A.K. Hartmann, R. Kree, T. Yasseri, Simulating discrete models of pattern formation by ion beam sputtering. J. Phys. Condens. Matter. 21, 224015 (2009)

48. K.C. Park, H.J. Choi, C.H. Chang, R.E. Cohen, G.H. McKinley, G. Barbastathis, Nanotextured silica surfaces with robust superhydrophobicity and omnidirectional broadband supertransmissivity. ACS.NANO 6, 3789 (2012)

49. C. Martella, D. Chiappe, P.D. Veneri, L.V. Mercaldo, I. Usatii, F.B. Mongeot, Self-organized broadband light trapping in thin film amorphous silicon solar cells. Nanotechnology 24, 225201 (2013)

50. X. Ye, X.D. Jiang, J. Huang, F. Geng, L.X. Sun, X.T. Zu, W.D. Wu, W.G. Zhang, Formation of broadband antireflective and superhydrophilic subwavelength structures on fused silica using onestep self-masking reactive ion etching. Sci. Rep. 5, 13023 (2015)

51. E.E. Tamayo, T. Hoshii, R. Tamaki, K. Watanabe, M. Sugiyama, Y. Okada, K. Miyano, Maskless fabrication of broadband antireflection nanostructures on glass surfaces. J. Opt 18, 064008 (2016)

52. M. Hayne, R.J. Young, E.P. Smakman, T. Nowozin, P. Hodgson, J.K. Garleff, P. Rambabu, P.M. Koenraad, A. Marent, L. Bonato, A. Schliwa, D. Bimberg, The structural, electronic and optical properties of $\mathrm{GaSb} / \mathrm{GaAs}$ nanostructures for charge-based memory. J. Phys. D Appl. Phys 46, 264001 (2013)

53. S. Deshpande, J. Heo, A. Das, P. Bhattacharya, Electrically driven polarized single-photon emission from an InGaN quantum dot in a GaN nanowire. Nature Commun. 4, 1675 (2013)

54. T. Konishi, E. Clarke, C.W. Burrows, J.J. Bomphrey, R. Murray, G.R. Bell, Spatial regularity of InAs-GaAs quantum dots: quantifying the dependence of lateral ordering on growth rate. Nature Sci. Rep. 7, 42606 (2015)

55. A. Cuenat, H.B. George, K.C. Chang, J.M. Blakely, M.J. Aziz, Lateral templating for guided self-organization of sputter morphologies. Adv. Mater. 17, 2845 (2005)

56. P. Karmakar, S.A. Mollick, D. Ghose, A. Chakrabarti, Role of initial surface roughness on ion induced surface morphology. Appl. Phys. Lett. 93, 103102 (2008)
57. J.H. Kim, J.S. Kim, J.M. Garcia, R. Cuerno, Role of nonlinearities and initial prepatterned surfaces in nanobead formation by ionbeam bombardment of $\mathrm{Au}(001)$ : Experiments and theory. Phys. Rev. B 87, 085438 (2013)

58. J.H. Kim, N.-B. Ha, J.S. Kim, M. Joe, K.R. Lee, R. Cuerno, Onedimensional pattern of Au nanodots by ion-beam sputtering: formation and mechanism. Nanotechnology 22, 285301 (2011)

59. Image processing software for nano-and micro scale analysis, Image Metrology. http://www.imagemet.com/. Accessed 2015

60. http://www.uni-leipzig.de/ unifit. Accessed 2015

61. R.M. Bradley, J.M.E. Harper, Theory of ripple topography induced by ion bombardment. J. Vac. Sci. Technol. A 6, 2390 (1988)

62. M.P. Harrison, R.M. Bradley, Blazed diffraction gratings produced by ion bombardment of pre-patterned solid surfaces. J. Appl. Phys. 121, 054308 (2017)

63. R. Gago, L. Vázquez, O. Plantevin, T.H. Metzger, J. MuñozGarcía, R. Cuerno, M. Castro, Order enhancement and coarsening of self-organized silicon nanodot patterns induced by ion-beam sputtering. Appl. Phys. Lett. 89, 233101 (2006)

64. D.P. Datta, T.K. Chini, Coarsening of ion-beam-induced surface ripple in Si: Nonlinear effect vs. geometrical shadowing. Phys. Rev. B 76, 075323 (2007)

65. J.M. Garcia, R. Gago, L. Vazquez, J.A.S. Garcia, R. Cuerno, Observation and modeling of interrupted pattern coarsening: surface nanostructuring by ion erosion. Phys. Rev. Lett. 104, 026101 (2010)

66. W. Hauffe, Faceting mechanism in the sputtering process. Phys. Stat. Sol. (a) 35, K93 (1976)

67. J.M. Garcia, M. Castro, R. Cuerno, Nonlinear ripple dynamics on amorphous surfaces patterned by ion beam sputtering. Phys. Rev. Lett. 96, 086101 (2006)

68. J.F. Moulder, W.F. Stickle, P.E. Sobol, K.D. Bomben, Handbook of X-Ray Photoelectron Spectroscopy. (Physical Electronics Inc., Chanhassen, 1995)

69. J.S. Noh, Aluminum silicide microparticles transformed from aluminum thin films by hypoeutectic interdiffusion. Nanoscale Res Lett 9, 312 (2014)

70. H. Sitzmann in RÖMPP Chemielexikon, Verlag Thieme, Stuttgart (online: https://roempp.thieme.de/roempp4.0/do/data/ RD-19-02443)

71. J.F. Ziegler, J.P. Biersack, M.D. Ziegler, J.P. Biersack, SRIM-The stopping and ranges of ions in matter. ANSI Std. (2010)

72. J.P. Biersack, W. Eckstein, Sputtering studies with the Monte Carlo Program TRIM.SP. Appl. Phys. A 34, 73 (1984)

73. W. Eckstein, Calculated sputtering, reflection and range values. MPI. für Plasmaphysik/Oberflächenphysik. Report IPP 9/132 (2002)

74. R. Kelly, N.Q. Lam, The sputtering of oxides part i: a survey of the experimental results. Rad. Eff 19, 39 (1973)

75. B. Rauschenbach, F. Frost, Destructive and constructive routes to prepare nanostructureson surfaces by low-energy ion beam sputtering. Proc. SPIE 9929, 99290A-1 (2016) 